\title{
Estudio florístico de Ficus (Moraceae) en el estado de Guerrero, México
}

\section{Floristic study of Ficus (Moraceae) in the state of Guerrero, Mexico}

\author{
Carlos Alberto Durán-Ramírez ${ }^{1,2}$, Rosa María Fonseca-Juárez y Guillermo Ibarra-Manríquez ${ }^{3 *}$ \\ ${ }^{1}$ Laboratorio de Plantas Vasculares, Facultad de Ciencias, Universidad Nacional Autónoma de México. Ciudad Universitaria, 04510 México, D. F., \\ México. \\ ${ }^{2}$ Dirección actual: Instituto de Ecología, A. C. Km. 2.5 antigua carretera a Coatepec 351, Colonia Congregación El Haya, 91070 Xalapa, Veracruz, \\ México. \\ ${ }^{3}$ Centro de Investigaciones en Ecosistemas, Universidad Nacional Autónoma de México. Antigua carretera a Pátzcuaro 8701, Colonia Ex Hacienda \\ San José de la Huerta, 58190, Morelia, Michoacán, México. \\ *Correspondencia: gibarra@oikos.unam.mx
}

\begin{abstract}
Resumen. Con base en salidas al campo y la revisión de ejemplares de herbario, se registran 13 especies de Ficus (Moraceae) en el estado de Guerrero, 4 pertenecen al subgénero Pharmacosycea (F.insipida, F. lapathifolia, F. maxima y $F$. yoponensis) y 9 al subgénero Urostigma (F. citrifolia, F. cotinifolia, F. crocata, F. membranacea, F. obtusifolia, $F$. pertusa, F. petiolaris, $F$. pringlei y $F$. velutina), al cual se añade un posible registro de $F$. aurea. Se incluye una clave para su identificación y se proporcionan descripciones, mapas de distribución, datos del hábitat y fenología de las especies, y se ilustran 6 de éstas. El bosque de galería y el bosque tropical caducifolio destacan por su riqueza de especies (8). Ficus lapathifolia restringe su distribución al bosque mesófilo de montaña y $F$. pringlei al bosque tropical caducifolio. Chilpancingo de los Bravo y Atoyac de Álvarez fueron los municipios con mayor cantidad de especies, con 11 y 9 especies, respectivamente. Por primera vez se registran para el estado: F. crocata, F. lapathifolia, F. membranacea, $F$. pringlei y F. yoponensis.
\end{abstract}

Palabras clave: amates, higueras, Ficus, Pharmacosycea, sicono, Urostigma.

\begin{abstract}
Based on herbarium specimens and on field explorations, 14 native species of Ficus (Moraceae) were recognized for Guerrero, Mexico. Four species are included in subgenus Pharmacosycea (Ficus insipida, F. lapathifolia, F. maxima and F. yoponensis) and 9 in subgenus Urostigma (F. citrifolia, F. cotinifolia, F. crocata, F. membranacea, F. obtusifolia, $F$. pertusa, F. petiolaris, F. pringlei and F. velutina), including a possible record of $F$. aurea. A key, descriptions, distribution maps, and phenology data of species are provided, and 6 of them are ilustrated. Riparian forest and tropical deciduous forest were the vegetation communities with the highest number of species (8). Ficus lapathifolia was restricted to cloud forest whereas $F$. pringlei shows the same condition in the tropical deciduous forest. The municipalities of Chilpancingo de los Bravo and Atoyac de Álvarez were the most diverse with 11 and 9 species, respectively. Ficus crocata, F. lapathifolia, F. membranacea, F. pringlei and F. yoponensis are recorded for the first time for the study area.
\end{abstract}

Key words: figs, Ficus, Pharmacosycea, syconium, Urostigma.

\section{Introducción}

Rzedowski (1991) propuso que la zona de mayor concentración de diversidad vegetal en México abarca los territorios de Chiapas y Oaxaca. El estado de Guerrero, cercano a estas entidades, también destaca por su riqueza florística. Villaseñor (2003) le asigna un total de 4648 especies, cifra sólo inferior a la que este autor anotó para Chiapas (7 573), Oaxaca (7 399), Veracruz (6 869), Jalisco (5 105) y Michoacán (4 672). Una estrategia para mejorar el conocimiento de la flora de áreas altamente diversas como

Recibido: 19 enero 2009; aceptado: 07 febrero 2010 la de Guerrero es enfocarse en el estudio de grupos con taxonomía compleja, con la idea de cuantificar de manera más confiable su riqueza y facilitar la determinación de sus especies.

En esta categoría puede incluirse sin duda el género Ficus (Moraceae), cuya diversidad mundial no se conoce con exactitud, aunque se calcula que incluye entre $700 \mathrm{y}$ 750 especies (Corner, 1962; Berg, 1989). En América, se le encuentra desde Florida (Estados Unidos de América) hasta el norte de Argentina, en distintos tipos de vegetación y generalmente en regiones con altitudes menores de 2 $500 \mathrm{~m}$, donde no se registran heladas (Burger, 1977; Berg, 1989). El género es inconfundible por el higo o sicono, un 
tipo de inflorescencia en la que las flores están aisladas casi por completo, ya que su único acceso desde el exterior es por medio de una apertura apical denominada ostíolo (Ibarra-Manríquez, 1991; Ibarra-Manríquez y Wendt, 1992). Esta inflorescencia, única entre las angiospermas, obliga a las miembros de Ficus a depender totalmente para su polinización de avispas de la familia Agaonidae, las que, a su vez, requieren necesariamente de las flores pistiladas para reproducirse; habitualmente, una especie de Ficus es polinizada por una de avispa (Berg, 1990, 2001; Gorelick, 2001; Weiblen, 2002; Cook y Rasplus, 2003, pero véase Machado et al., 2005). Por otra parte, una vez que maduran los siconos constituyen una importante fuente de alimento para una amplia gama de animales, en especial, aves y murciélagos (Ibarra-Manríquez, 1991; Berg, 2001; Shanahan et al., 2001).

En la República Mexicana se han estimado entre 21 y 34 especies nativas de Ficus (Standley 1917, 1922; Serrato et al., 2004; Villaseñor, 2004). De los trabajos florísticos pioneros destaca el de Standley (1917, 1922), donde se describen brevemente las especies del género para México y Centroamérica, con una clave para su identificación. Otros trabajos similares más recientes son el de Ibarra-Manríquez y Wendt (1992), restringido al estado de Veracruz, el de Quintana y Carvajal (2001) para Jalisco y de Piedra-Malagón et al. (2006) para Morelos; el de Pennington y Sarukhán (2005), no restringido a un solo estado de México, que incluye tres especies (Ficus cotinifolia Kunth, F. petiolaris Kunth y F. tecolutensis (Liebm.) Miq.), y el de Carvajal (2007) donde se describen 13 especies de la región del Bajío y zonas adyacentes.

Standley (1922) menciona explícita o implícitamente 7 especies de Ficus presentes en Guerrero (F. cotinifolia, F. lapathifolia (Liebm.) Miq., F. involuta (Liebm.) Miq., $F$. padifolia Kunth, $F$. petiolaris, $F$. radulina $\mathrm{S}$. Watson y $F$. segoviae Miq.). Una revisión de los listados florísticos regionales publicados para el estado añade otras 15 (Fonseca y Lozada, 1993; Lozada, 1994; Diego-Pérez y Lozada-Pérez, 1994; Gual, 1995; Verduzco y Rodríguez, 1995; Gallardo, 1996; Vargas y Pérez, 1996; DiegoPérez, 2000; Velázquez et al., 2003; Carreto y Almazán, 2005): F. citrifolia Mill., F. costaricana (Liebm.) Miq., F. glabrata Kunth, F. glaucescens (Liebm.) Miq., F. hemsleyana Standl., F. inamoena Standl., F. insipida Willd., F. lentiginosa Vahl, F. maxima Mill., F. mexicana (Miq.) Miq., F. obtusifolia Kunth, F. pertusa L.f., F. radula Willd., F. tuerckheimii Standl. y $F$. velutina Humb. et Bonpl. ex Willd.

Las inconsistencias en la riqueza e identidad de las especies de Ficus en Guerrero obedecen, entre otras causas, a que la taxonomía de las especies neotropicales, especialmente las del subgénero Urostigma, es compleja
(Berg y Simonins, 1981; Berg, 1989, 2007). Por ello, varios autores han reconocido algunas especies como complejos taxonómicos que despliegan un amplio margen de variabilidad (Berg y Simonins, 1981; Berg, 1989, 2007; Ibarra-Manríquez y Wendt, 1992; Piedra-Malagón et al., 2006), mientras que otros las separan en especies o categorías subespecíficas distintas (Burger, 1974; Carvajal, 1995, 2007; Carvajal y Peña-Pinela, 1997; Carvajal et al., 2001). Es por lo anterior que el propósito medular de esta contribución consiste en actualizar el conocimiento florístico del género Ficus en Guerrero, aportando una clave y descripciones que faciliten su determinación.

\section{Materiales y métodos}

Área de estudio. El estado de Guerrero se sitúa hacia el SE de la República Mexicana, entre los $16^{\circ} 18^{\prime}$ y $18^{\circ} 48^{\prime} \mathrm{N}$ y los $98^{\circ} 03^{\prime}$ y $102^{\circ} 12^{\prime} \mathrm{O}$. Esta entidad colinda con Michoacán, Estado de México, Morelos, Puebla, Oaxaca y el océano Pacífico, con una extensión territorial de 63794 km² y está subdividido en 75 municipios agrupados en cuatro grandes regiones fisiográficas (Figueroa de Cotín, 1980): Sierra de Taxco, Depresión del Balsas, Sierra Madre del Sur y Costa.

Geológicamente, Guererro se encuentra dentro de 2 provincias morfotectónicas (Ferrusquía-Villafranca, 1998): i) Faja Volcánica Transmexicana, y ii) Sierra Madre del Sur. De acuerdo con este autor, la primera de estas provincias ocupa la parte occidental del estado y las formas dominantes del terreno fueron producidas por actividad volcánica del Cenozoico medio al tardío, con cuerpos sedimentarios clásticos del Cenozoico tardío. La provincia de la Sierra Madre del Sur presenta cuerpos de roca de edad precámbrica, paleozoica, mesozoica y cenozoica; los datos geológicos son escasos si se considera que es la de mayor complejidad en México, el territorio de Guerrero incluye 4 de las 13 subdivsiones que la componen.

En la entidad se presentan 10 unidades edafológicas y 3 tipos de suelo cubren cerca del $65 \%$ de su territorio (Meza y López, 1997): a) los regosoles, en la región norte (Tierra Caliente, cuenca del Balsas y sierra del Norte), en la sierra Madre del Sur y en algunas regiones de la Costa, b) los cambisoles, que se distribuyen principalmente en el noroeste y parte sureña de Guerrero, así como en la región de la montaña, Costa Grande, Tierra Caliente y Centro y, c) los litosoles, que se encuentran básicamente al centronorte y centro-sureste, por ejemplo, en la sierra Madre del Sur, costa Chica y cañón del Zopilote. Otros tipos de suelo son andosoles, acrisoles, feozems, fluvisoles, luvisoles, rendzinas y vertisoles.

Meza y López (1997) presentan un mapa y describen 
5 unidades mesoclimáticas en la entidad (muy cálida, cálida, semicálida, templada y semifría). Las 2 primeras están situadas desde el nivel del mar hasta $1300 \mathrm{~m}$ de altitud y cada una tiene 3 variantes de humedad (húmeda, subhúmeda y semiseca), mientras que la unidad semicálida y la templada se ubican entre 1300 y $2800 \mathrm{~m}$; la primera tiene 3 variantes de humedad (muy húmeda, húmeda y subhúmeda); la segunda tiene 2, una muy húmeda y otra subhúmeda. Finalmente, la unidad mesoclimática semifría se considera muy húmeda y se ubica por arriba de 2800 m snm.

De acuerdo con la clasificación de Rzedowski (1978), las comunidades vegetales que se encontraron en el estado son: bosque de coníferas (bosque de Abies, bosque de Juniperus y bosque de Pinus), bosque de Quercus, bosque espinoso, bosque mesófilo de montaña, bosque tropical caducifolio, bosque tropical perennifolio, bosque tropical subcaducifolio, manglar, matorral xerófilo, palmar, pastizal y varios tipos de vegetación acuática y subacuática (e.g. bosque de galería). Meza y López (1997) presentan un mapa con la distribución de 10 coberturas vegetales que reconocen en Guerrero. Finalmente, Palacio-Prieto et al. (2000) identifican 11 tipos de vegetación y anotan la extensión y el porcentaje que ésta representa para el estado: bosque de encino (6 $\left.411 \mathrm{~km}^{2} ; 10.1 \%\right)$, bosque mesófilo de montaña (1 $\left.570 \mathrm{~km}^{2} ; 2.5 \%\right)$, bosque de pino-encino (12 $\left.275 \mathrm{~km}^{2} ; 19.3 \%\right)$, bosque de pino (1 $\left.271 \mathrm{~km}^{2} ; 2 \%\right)$, dunas $\left(121 \mathrm{~km}^{2} ; 0.2 \%\right)$, manglar $\left(95 \mathrm{~km}^{2} ; 0.1 \%\right)$, sabana (266 $\left.\mathrm{km}^{2} ; 0.4 \%\right)$, selva baja caducifolia y subcaducifolia (18 222 $\left.\mathrm{km}^{2} ; 28.7 \%\right)$, selva mediana caducifolia y subcaducifolia (1 $\left.509 \mathrm{~km}^{2} ; 2.4 \%\right)$, palmar $\left(273 \mathrm{~km}^{2} ; 0.4 \%\right)$ y popal-tular (74 $\left.\mathrm{km}^{2} ; 0.1 \%\right)$.

Método. Se llevó a cabo una revisión bibliográfica de listados florísticos, publicaciones taxonómicas y floras regionales para recopilar una lista de las especies nativas de Ficus en Guerrero, y se consultaron los ejemplares depositados en los herbarios $\mathrm{CH}$, ENCB, F, FCME, HUAP, HUMO, IEB, INIF, MEXU, MO, UAMIZ y XAL. Con esta información y las observaciones en el campo, se elaboró una clave de identificación, se hicieron descripciones, mapas de distribución de las especies, así como ilustraciones para algunas de éstas. Debido a que el único ejemplar que se ha colectado de F. yoponensis Desv. en la zona de estudio carece de estructuras reproductivas, su descripción se complementó con base en material proveniente de entidades vecinas. En el trabajo también se incluye $F$. aurea Nutt., que hasta el momento no ha sido registrada para Guerrero, pero que sin duda debe encontrarse en sus bosques mesófilos; la descripción de esta especie también se basa en colectas efectuadas en estados colindantes.

Los tipos de vegetación donde se distribuyen las especies fueron adaptados a la clasificación de Rzedowski (1978). Los nombres comunes y sinónimos que se citan para las especies son únicamente los que se han registrado para Guerrero. Para los sinónimos se tomaron en consideración los criterios de Ibarra-Manríquez y Wendt (1992), Berg y Villavicencio (2004) y Berg (2007). Las abreviaturas de los autores se basan en Villaseñor (2001).

\section{Resultados}

De las 22 especies nativas de Ficus que se citaban previamente para Guerrero, en el presente trabajo sólo se reconocen 13; de éstas, 4 pertenecen al subgénero Pharmacosycea (F. insipida, F. lapathifolia, F. maxima y F. yoponensis) y el resto al subgénero Urostigma ( $F$. citrifolia, F. cotinifolia, F. crocata (Miq.) Miq., F. membranacea C. Wright, $F$. obtusifolia, $F$. pertusa, $F$. petiolaris, $F$. pringlei $\mathrm{S}$. Watson y $F$. velutina). Se citan por primera vez como parte del contingente florístico guerrerense las siguientes especies: F. crocata, F. lapathifolia, F. membranacea, F. pringlei y $F$. yoponensis.

El intervalo altitudinal de distribución del género abarca desde el nivel del mar hasta los $2100 \mathrm{~m}$, de manera que la mayoría de sus especies se encuentran en los tipos de vegetación localizados a bajas altitudes (por ejemplo, bosque tropical caducifolio, bosque tropical subcaducifolio o bosque de galería) y son menos frecuentes en bosque de Quercus y bosque mesófilo de montaña. Ficus lapathifolia restringe su distribución a este último tipo de cobertura vegetal, en tanto que $F$. pringlei hace lo propio en el bosque tropical caducifolio. De las especies registradas en el área de estudio, 3 son endémicas de México ( $F$. lapathifolia, $F$. petiolaris y $F$. pringlei), en tanto que el resto muestran una distribución más amplia, ya que alcanzan localidades ubicadas en distintos países de Centro y/o Sudamérica. Las especies del género más frecuentemente colectadas son: $F$. cotinifolia (140 ejemplares), F. insipida (73) y F. crocata (57). En 50 de los 75 municipios de Guerrero, se han colectado especies de Ficus, sobresaliendo Chilpancingo de los Bravo (90 registros y 11 especies) y Acapulco de Juárez ( 57 y 8, respectivamente). Cabe destacar que Atoyac de Álvarez, con sólo 21 registros, presenta 9 especies.

\section{Descripciones}

1. Ficus aurea Nutt. N. Amer. Sylv. 2(4): pl. 43. 1846. F. tuerckheimii Standl. Contr. U.S. Natl. Herb. 20(1): 13. 1917.

Árboles hemiepífitos o estranguladores, caducifolios o perennifolios, de (6) 20-45 $\mathrm{m}$ de alto, el tronco con una 


\section{Clave de identificación}

1a. Árboles de crecimiento independiente, enraizados en el suelo; siconos solitarios por nudo, amarillos, verde amarillos o verdes

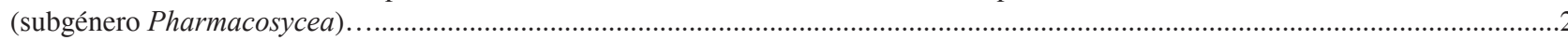
1b. Árboles estranguladores, rupícolas o enraizados en el suelo; siconos pareados por nudo, de color amarillo, naranja, negro rojo o

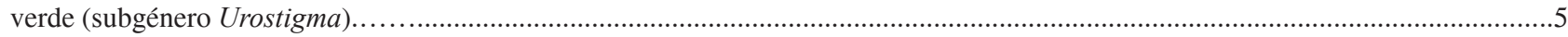

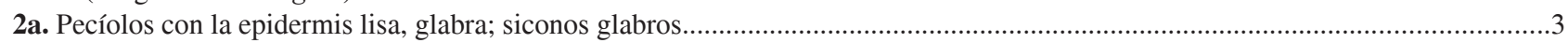

2b. Pecíolos con la epidermis que se desprende en pequeñas escamas, escaso pubescente; siconos pubescentes................................. 4 3a. Hojas obovadas o elípticas, con venas secundarias tenues; siconos con flores blancas; árboles no restringidos a comunidades

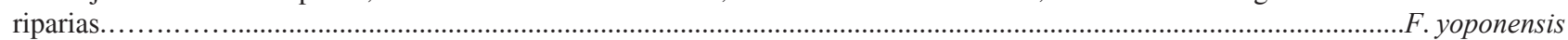
3b. Hojas elíptico lanceoladas, con venas secundarias conspicuas; siconos con flores rojizas; árboles generalmente riparios...

4a. Pecíolo cuya epidermis se exfolia por medio de escamas, lámina escabrosa, de hasta $7.8 \mathrm{~cm}$ de ancho; siconos con flores

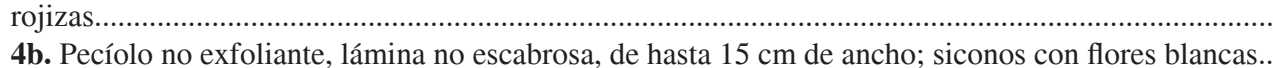

4b. Pecíolo no exfoliante, lámina no escabrosa, de hasta $15 \mathrm{~cm}$ de ancho; siconos con flores blancas
5a. Árboles con la corteza amarilla; hojas cordiformes, con domacios de color blanco por el envés..

.F. maxima

F. lapathifolia

6a. Brácteas basales evidentes, cubriendo hasta tres cuartas partes del sicono.

6b. Brácteas basales no evidentes o sin sobrepasar una cuarta parte del sicono.......................................................................

7a. Hojas elípticas u ovadas, con la base redondeada a ligeramente truncada; árboles del bosque mesófilo de montaña..............F. aurea

7b. Hojas obovadas o elípticas, con la base cuneada o atenuada; árboles que se distribuyen en diversos tipos de vegetación.

8a. Plantas con siconos sésiles.....

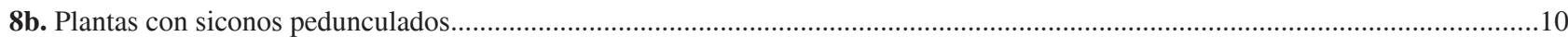

9a. Pecíolos casi tan largos como la lámina, el primer par de venas secundarias con una inclinación de 60-70 yema foliar terminal glabra.......................................................................................................................................... membranacea 9b. Pecíolos con menor longitud que la de la lámina, el primer par de venas secundarias con una inclinación de $35-50^{\circ}$; yema foliar

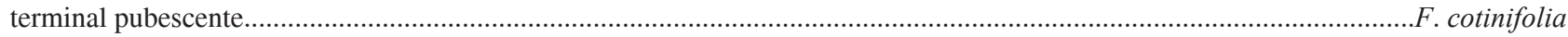
10a. Lámina con ápice acuminado, pecíolos de $2.5-12 \mathrm{~cm}$ de largo y con exudado translúcido; siconos obpiriformes..........F. citrifolia 10b. Lámina sin acumen en el ápice, pecíolos menores de $5 \mathrm{~cm}$ de largo y con exudado blanco; siconos esféricos, raramente piriformes.....

11a. Lámina foliar 0.8-1.2 veces más larga que ancha, pecíolos de $0.5-2 \mathrm{~cm}$ de largo; ostíolo del sicono prominente, cónico; árboles del bosque tropical caducifolio.

11b. Lámina foliar 1.5-3.4 veces más larga que ancha, pecíolos de 1.5-4.3 cm de largo; ostíolo del siconos hundido, aplanado o ligeramente prominente; árboles no restringidos al bosque tropical caducifolio...

12a. Hojas con envés cubierto con tricomas rojizos o pardo amarillos, raramente glabro; siconos sin máculas evidentes, velutinos, raramente glabrescentes. ..F. velutina 12b. Hojas con envés glabro, a veces escaso pubescente, pero nunca con tricomas rojizos o pardo amarillos; siconos con máculas evidentes, glabros o pilósulos.

13a. Lámina foliar de 1-1.6 cm de ancho; siconos glabros, de $0.8-1.3 \mathrm{~cm}$ de diámetro, con flores blancas, con el ostíolo hundido en

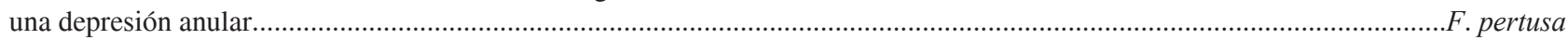
13b. Lámina foliar de (2.6) 3.9-7.2 cm de ancho; siconos pilósulos, de 1.2-2.7 cm de diámetro, con el ostíolo aplanado a ligeramente prominente.

forma irregular, frecuentemente con oquedades, corteza parda o pardo grisácea, con exudado blanco, copa amplia y redondeada, verde oscura. Yema foliar terminal de 3$13 \mathrm{~mm}$ de largo, 3-4 mm de ancho, parda o negra, glabra; entrenudos de 5-12 mm de largo, 4-6 mm de ancho, verdes, pardos o amarillo grisáceos, glabros. Pecíolo de 25-60 mm de largo, 2-3 mm de ancho, amarillo, pardo o pardo verde, ligeramente acanalado por el haz, glabro; lámina foliar de 6.5-11 cm de largo, 3.5-6.5 cm de ancho, 1.3-2.1 veces más larga que ancha, elíptica u ovada, verde grisácea a parda, membranácea o cartácea, base redondeada o ligeramente truncada; ápice obtuso o ligeramente apiculado; haz verde pardo, verde amarillo o pardo, glabro; envés verde, verde opaco o ligeramente pardo, glabro, venas secundarias amarillas, 9 a 12 pares, con la vena central y las secundarias prominentes a tenuemente marcadas. Siconos de 8-12 mm de largo, 8-12 mm de diámetro, esféricos, de color naranja, negro rojo o verde en fresco, pardo a verde amarillo en material seco, con pequeñas máculas pardas, redondeadas, glabros; ostíolo de 1-1.5 mm de diámetro; brácteas basales pareadas, de 4-8 mm de largo, 3-7 $\mathrm{mm}$ de ancho, pardas o pardo verdosas, ápice redondeado a ligeramente agudo, 
glabras; pedúnculo ausente o de hasta $10 \mathrm{~mm}$ de largo, verde o pardo, glabro.

\section{Resumen taxonómico}

Material examinado. OAXACA. Mpio. San Miguel Chimalapa: cerro Sabinal, $2 \mathrm{~km}$ al SO de cerro Guayabitos, $3 \mathrm{~km}$ en línea recta al NNO de Díaz Ordaz (1644’00”N, 94¹1'30"O), T.L. Wendt et al. 4665 (MEXU, MO); San Miguel Suchixtepec: San Miguel Suchixtepec (16²'00”N, 95'56'00'O), P. Tenorio et al. 18387 (MO); Valle Nacional: cerro Mirador, $15 \mathrm{~km}$ al NNO de Valle Nacional (1746’33”N, 96¹8'12”O), G. Ibarra et al. 3823 (MEXU, MO).

\section{Comentarios taxonómicos}

En otros estados de la República Mexicana se le localiza en bosques tropicales húmedos y mesófilos de montaña (Serrato et al., 2004), desde el nivel del mar hasta los $2450 \mathrm{~m}$ de altitud. Debido a la importante área que ocupa el bosque mesófilo de montaña en Guerrero, es altamente probable que esta especie se encuentre en su territorio, además de que prácticamente se ha colectado en todos sus estados vecinos (México, Michoacán, Puebla y Oaxaca; G. Ibarra-Manríquez, datos no publicados). La especie presenta hojas y frutos muy variables, lo que aunado a su amplia distribución (desde Estados Unidos de América a Sudamérica y Las Antillas) hace difícil establecer límites claros entre especies afines, las cuales conforman el complejo taxonómico F. aurea (Berg, 1989, 2007). Una ilustración de esta especie bajo el nombre de $F$. tecolutensis se encuentra en Pennington y Sarukhán (2005).

2. Ficus citrifolia Mill.Gard.Dict (ed.8)1768. F. lentiginosa Vahl. Enum. Pl. 2: 183. 1806. (Fig. 1A, 2).

Nombres comunes. Amate, amate prieto, amaiskitle, amezquite, capulincillo, palo liro.

Árboles hemiepífitos, estranguladores o rupícolas, caducifolios o perennifolios, de 4-15 m de alto, tallos monopódicos, fuste recto a sinuso, corteza parda o pardo grisácea, copa amplia y redondeada, verde oscuro. Yema foliar terminal de 10-24 mm de largo, 3-6 mm de ancho, parda en material seco, glabra; entrenudos de 17-35 mm de largo, 4-8 mm de ancho, amarillo grisáceos, estriados, glabros, con exudado translúcido. Pecíolo de 25-75 (120) mm de largo, 1.5-3 mm de ancho, amarillo, pardo o verde, estriado, frecuentemente acanalado por el haz, glabro; lámina foliar de (7.2) 12.5-16 (21.5) cm de largo, (4.5) 6.710.5 (13) cm de ancho, 1.6-1.7 veces más larga que ancha, elíptica a ovada, verde grisácea a parda, membranácea o cartácea, base redondeada a ligeramente truncada; ápice con un acúmen de 6-10 $\mathrm{mm}$ de largo; haz verde pardo a verde amarillo o pardo, glabro, envés verde, verde opaco o ligeramente pardo, glabro, venas secundarias amarillas, 6 a 13 pares, opuestos en el primer par y los demás alternos, con la vena central y las secundarias más o menos prominentes. Siconos de 6-12 (16) mm de largo, 5-10 (14) $\mathrm{mm}$ de diámetro, obpiriformes, verdes a rojizos en fresco, pardos a verde amarillos cuando secan, con pequeñas máculas pardas, redondeadas, glabros; ostíolo de 1.5-4 $\mathrm{mm}$ de diámetro; brácteas basales pareadas, de 1-2 mm de largo, 1.5-3 mm de ancho, pardas, ápice redondeado a ligeramente agudo, glabras; pedúnculo de 3-7 (10) mm de largo, verde o pardo, glabro.

\section{Resumen taxonómico}

Material examinado. Mpio. Acapulco de Juárez: Acapulco and vicinity (16 $51^{\circ} 47^{\prime \prime N}$, 98 $\left.53^{\circ} 47^{\prime \prime O}\right)$, E.A. Palmer 355 (F, MO); cerca de Puerto Marqués (16 53'53“N, 9952‘23“'O), F. Miranda 8420 (MEXU), Idem, L. Paray 2310 (MEXU); Cumbres de Llano Largo (1653‘53“N, 9952‘13“O), J. Sánchez s. n. (ENCB). Mpio. Atoyac de Álvarez: $2 \mathrm{~km}$ adelante de Santiago de la Unión $\left(17^{\circ} 12^{‘} 39^{\prime} \mathrm{N}, 100^{\circ} 26^{\prime} 19^{\prime \prime O}\right)$, R.M. Fonseca 722 (FCME, IEB, MEXU); $2 \mathrm{~km}$ al SO del ejido El Molote $\left(17^{\circ} 25^{\circ} 39.08^{\prime} \mathrm{N}, 100^{\circ} 14^{`} 07.85^{\prime \prime O}\right)$, S. Ollinger 5 (FCME, IEB, MEXU); $500 \mathrm{~m}$ de San Andrés a El Paraíso (17 $\left.15^{\circ} 25^{\prime \prime} \mathrm{N}, 100^{\circ} 20^{\prime} 56^{\prime \prime O}\right)$, G. Ibarra et al. 5941 (IEB). Mpio. Chilpancingo de los Bravo: $2 \mathrm{~km}$ al $\mathrm{N}$ de Agua de Obispo $\left(17^{\circ} 18^{\prime} 50^{\prime \prime} \mathrm{N}, 9^{\circ} 28^{\circ} 00^{\prime \prime O}\right)$, R.M. Fonseca 1724 (FCME, IEB, MEXU); $3 \mathrm{~km}$ al $\mathrm{N}$ de El Ocotito sobre la carretera federal a Acapulco $\left(17^{\circ} 17^{`} 38^{\prime \prime} \mathrm{N}\right.$, 99²8‘17“O), C.A. Durán 129 (FCME, MEXU); Rincón Viejo $\left(17^{\circ} 17^{\circ} 40^{\circ} \mathrm{N}, 99^{\circ} 30^{\circ} 00^{\prime \prime O}\right)$, H. Kruse 1279 (FCME, MEXU), s. n. (MEXU); rio Azinyehualco, al $\mathrm{N}$ de Zoyaltepec $\left(17^{\circ} 20^{\circ} 45^{\prime \prime} \mathrm{N}, 9^{\circ} 33^{\circ} 38^{\circ}\right.$ “O), L.C. Rodríguez 383 (IEB, MEXU); Rincón de la Vía, Barranca del Potrero

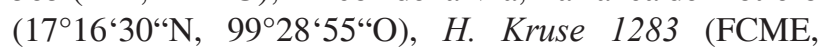
MEXU). Mpio. Coahuayutla de José María Izazaga: La Vainilla, $2.8 \mathrm{~km}$ al N (18¹1'29“N, 101²9“46“O), J. Calónico 15161 (FCME, MEXU); San Cristobal, $2.8 \mathrm{~km}$ al NE (1808‘51“N, 101³1‘04“O), J. Calónico 13677 (FCME). Mpio. José Azueta: $1 \mathrm{~km}$ antes de la desviación a Ciudad Altamirano, por la carretera ZihuatanejoLázaro Cárdenas $\left(17^{\circ} 43^{\prime 2} 21^{\prime \prime N}, 101^{\circ} 55^{\prime} 57^{\prime \prime O}\right)$, M. Gual 557 (FCME, MEXU); alrededores de El Zapote al $\mathrm{N}$ del poblado $\left(17^{\circ} 58^{\circ} 46^{\prime \prime N}, 101^{\circ} 22^{\prime} 11^{\prime \prime O}\right)$, R.M. Fonseca 1213 (FCME, MEXU); aproximadamente $230 \mathrm{~m}$ al NE del caserio La Vainilla, camino al Calabazalito $\left(17^{\circ} 42^{`} 00^{\prime} \mathrm{N}\right.$, 101³1‘30“O), C. Gallardo 432 (FCME, MEXU); cerro situado al O del mirador del Parque Ecológico La 
Vainilla $\left(17^{\circ} 42^{`} 00^{\prime} \mathrm{N}, 101^{\circ} 31^{`} 30^{\circ} \mathrm{O}\right)$, C. Gallardo 680 (FCME, MEXU). Mpio. Mpio. Ometepec: Ometepec (16 41'08”N, 98²4'19”O), L. García s. n. (FCME). Mpio. Quechultenango: proximidades a Quechultenango (17²4'50”'N, 99¹4'27’'O), C. Tejeda s. n. (MEXU).

\section{Comentarios taxonómicos}

Árboles presentes en el bosque de galería, bosque de Pinus, bosque de Quercus y bosque tropical caducifolio, entre 15 y $1,750 \mathrm{~m}$ snm. Florece y fructifica durante todo el año, mayormente de enero a octubre. Esta especie se distribuye en México desde Nayarit hasta Chiapas, así como en la península de Yucatán; fuera del país se le encuentra desde Florida (Estados Unidos de América) hasta el sur de Paraguay y Las Antillas. Especie que despliega una alta variación en su morfología, por lo que Berg (1989, 2007) la incluye como parte de un complejo taxonómico denominado $F$. citrifolia, el cual incluye, entre otras especies, a F. amazonica (Miq.) Miq., F. britonii Bold., $F$. dugandii Standl., F. guarantica Chodat y F. subandina Dugand.

3. Ficus cotinifolia Kunth. Nov. Gen. Sp. (quarto ed.) 2: 49.1817. (Fig. 1B, 3).

Nombres comunes. Amaiskitle, amaiskitl, amezquite, amezquite blanco, camichín, camuchín, camuchina, saiba blanca, zalate.

Árboles hemiepífitos, estranguladores o rupícolas, caducifolios, de 4-20 m de alto, con tallos monopódicos, con oquedades entre las raíces aéreas, a veces con contrafuertes, corteza lisa, pardo gris, parda oscura, con exudado blanco a ligeramente amarillo, abundante, copa amplia y redondeada, verde pálida. Yema foliar terminal de 5-17 mm de largo, 2.3-5.5 (7) $\mathrm{mm}$ de ancho, verde o verde amarilla en fresco, parda a negruzca en material seco, densamente pubescente, con tricomas blancos o amarillos, en ocasiones glabrescente; entrenudos de (4) 11-36 (42) mm de largo, (2) 3.5-7 mm de ancho, pardos o verde pardo, estriados, glabros o escasamente pubescentes. Pecíolo de (9) 16-35 (45) mm de largo, 0.9-2.1 mm de ancho, pardo, verde amarillo o grisáceo, con un canal somero por el haz, corrugado y escasamente pubescente, en ocasiones con una glándula negra al comienzo de la vena media, por el lado del envés; lámina foliar de 2.7-9 (12.5) cm de largo, (2.8) 4.7-7 cm de ancho, 1.3-1.5 veces más larga que ancha, lámina elíptica, obovada u ovada, parda o negruzca, coriácea, cartácea o raramente membranácea; base redondeada, truncada o cuneada; ápice redondeado u obtuso, raramente obtuso; haz verde pardo, ligeramente viloso o glabro; envés verde o verde opaco, glabro o ligera a densamente viloso siendo más abundantes los tricomas en la vena central y en las venas secundarias, éstas últimas amarillas, 5 a 9 pares, el primero opuesto y los demás alternos. Siconos sésiles, de 4-6.5 mm de largo, 7-10.5 mm de diámetro, esféricos, verdes, verde amarillos, rojizos en fresco, verde amarillos o pardos en material seco, con máculas oscuras abundantes y de distintos tamaños, glabros a ligeramente pubescentes; ostíolo de 1-2 mm de diámetro; brácteas basales de 4-8 mm de largo, 2-6 mm de ancho, pardas o claras, con el ápice redondeado, no visibles o alcanzando hasta un tercio de la longitud del sicono, 2 a 4 partidas, densamente pubescentes por ambas caras.

\section{Resumen taxonómico}

Material examinado. Mpio. Acapulco de Juárez: $2 \mathrm{~km}$ al O de Puerto Marqués (1653'53'N, 9952'13'O), W. López 1119 (ENCB, MEXU, XAL), 1232 (ENCB, MEXU, $\mathrm{XAL}) ; 2.5 \mathrm{~km}$ al $\mathrm{O}$ de Puerto Marqués (16 $53^{\circ} 53^{\prime} \mathrm{N}$, 9952'23”O), W. López 557, 712 (MEXU), 1127 (ENCB, MEXU, XAL), 1158 (ENCB, MEXU, MO), 1190 (MEXU, XAL); Isla de la Roqueta (1653'53'N, 9952'13”O), $D$. Ramírez 12 (MEXU), s. n. (MEXU); Parque Nacional El Veladero INFONAVIT, parte posterior de la Col. Francisco Villa (1655'54”N, 9953'12”O), N. Noriega 117 (ENCB, FCME, IEB, MEXU), 232 (IEB, MEXU); Puerto Marqués (1641'25”N, 99॰37'35”O), F. Chiang 752 (ENCB, MEXU, MO); terminal de la Escénica Acapulco (16 51'47'N, 98 53'47'O), L. Boege 1430 (MEXU); Viveros El Huayacán, La Poza (1653'53”N, 9952’13”O), W. López 758 (MEXU). Mpio. Ahuacuotzingo: Ajuatetla (17³7'06”N, 9907'33”O), J. Casarrubias 122 (FCME, MEXU, XAL); Idem, M.J. Sánchez 47 (MEXU, XAL); Idem, N. Diego 7190 (FCME, MEXU). Mpio. Alcozauca de Guerrero: Alcozauca, Barranca del Agua Buena (17²7'48'N, 98²3'01'O), J.L. Viveros 390 (MEXU, MO). Mpio. Alpoyeca: $1 \mathrm{~km}$ al NO de Tecoyo (17³6’10”N, 98²9’29”O), J. Calónico 1576 (FCME); $1.5 \mathrm{~km}$ al E de Tecoyo, cañada Tecuane $\left(17^{\circ} 35^{\prime} 20^{\prime \prime} \mathrm{N}\right.$, 99²8'28'O), J. Calónico 1654 (FCME, HUAP, MEXU); $1.5 \mathrm{~km}$ al S de Tecoyo (17³4'40”N, 98²9'29'O), J. Calónico 2121 (FCME, HUAP); Mpio. Apaxtla: $2.2 \mathrm{~km}$ al SE de Tlatzala (1803'56”N, 99॰52'59”O), E. Chávez 104 (FCME); $2.5 \mathrm{~km}$ al SE de Tlatzala $\left(18^{\circ} 03^{\prime} 56^{\prime \prime} \mathrm{N}\right.$, 9952'59’'O), E. Velasco s. n. (FCME). Mpio. Arcelia: Los Limones, en la cañada el Naranjo, Campo Morado (18 12'27'N, 10007'45”O), R. Cruz 6516 (FCME). Mpio. Atenango del Río: $2 \mathrm{~km}$ al $\mathrm{SO}$ de Coahuixtla (18 $\left.21^{\prime} 22^{\prime \prime} \mathrm{N}, \quad 99^{\circ} 07^{\prime} 35^{\prime} \mathrm{O}\right), \quad$ R.C. Bustamante 342 (HUMO); $2.36 \mathrm{~km}$ al NO de Tuzantlan $\left(18^{\circ} 12^{\prime} 52^{\prime \prime} \mathrm{N}\right.$, 99¹1'58”O), R. Cruz 6996 (FCME, MEXU). Mpio. Atlixtac: $0.4 \mathrm{~km}$ al NO de Santa Isabel $\left(17^{\circ} 35^{\prime} 26^{\prime}\right.$ N, 9900'27'O), F. Guerrero 108 (FCME); $11 \mathrm{~km}$ al NO de 
Chiepetepec $\left(17^{\circ} 29^{\prime} 00^{\prime \prime} \mathrm{N}, 98^{\circ} 48^{\prime} 00^{\prime} \mathrm{O}\right)$, C.A. Durán 68 (ENCB, FCME, IEB, MEXU). Mpio. Benito Juárez: cerro San Nicolás, Laguna de Mitla $\left(17^{\circ} 12^{\prime} 31^{\prime}\right.$ N, 100²6'03”O), L. Lozada 569 (ENCB, FCME, MEXU). Mpio. Buenavista de Cuéllar: $3 \mathrm{~km}$ al $\mathrm{O}$ de la posa del Burro (18²7’30”N, 99²4'26”O), F. Terán 488 (FCME, MEXU); $6 \mathrm{~km}$ al $\mathrm{N}$ de Buenavista de Cuellar, carretera federal Cuernavaca-Iguala (18³7'52’'N, 99²4’09”O), C. A. Durán 93 (FCME, IEB, MEXU); Cieneguillas, $11 \mathrm{~km}$ al SO de Buenavista $\left(18^{\circ} 24^{\prime} 36^{\prime \prime} \mathrm{N}, 99^{\circ} 28^{\prime} 36^{\prime} \mathrm{O}\right)$, J.C. Soto 8737 (IEB, MEXU); puente La Cañada, a orillas del río en el Cañón del Zopilote, $3 \mathrm{~km}$ al $\mathrm{S}$ de la desviación a Buenavista de Cuellar (18³7’32'”N, 99²4’06”O), C.A. Durán 97, 99 (FCME, MEXU). Mpio. Chilpancingo de los Bravo: $3 \mathrm{~km}$ al O de Chilpancingo (17 33'14'N, 99²9'59”O), M. Blanco 104 (ENCB), 126 (ENCB, MEXU); $3 \mathrm{~km}$ al $\mathrm{S}$ de Acahuizotla (17'21'35'N, 99²7'43"O), F. Chiang 719 (ENCB, MEXU, MO); 3 km NO de Chaucingo (17³4'25'N, 99³1'04”O), M. Luna 66 (FCME); $7 \mathrm{~km}$ al E de Acahuizotla (17²2'59'N, 99²7’04”O), A. Núñez 63 (FCME); $16 \mathrm{~km}$ al NO de Chilpancingo sobre la carretera que va a Chichihualco (17³5’32”N, 99³1'11'O), C.A. Durán 126 (ENCB, IEB, MEXU); al O de Chilpancingo (17³3' 14'N $99^{\circ} 39^{\prime} 59^{\prime}$ 'O), $J$. Chavelas 6 (INIF, MEXU); camino a Chichihualco, a 4 mi de la conjunción con la carretera 95 cerca de Chilpancingo (17³3'14”N, 99³9'59'O), W.L. Graham 1224 (MEXU); camino a la estación de microondas El Alquitrán (17²6'40”N, 99²9'01'O), L. Lozada 2346 (FCME, IEB, MEXU); Joya de El Zapote, $6 \mathrm{~km}$ al O de la desviación a Chilchihualco, la desviación está a $1.5 \mathrm{~km}$ al N de Chilpancingo (17³3'14'N, 99²9'59'O), R. Torres 1183 (MEXU); km 7 de la carretera ChilpancingoChihihualco (17³6'0”N, 99³2'50”O), H. Kruse 1999 (FCME, MEXU, MO); Rincón de la Vía $\left(17^{\circ} 17^{\prime} 15^{\prime}\right.$ N, 99²8'55'O), H. Kruse 454 (ENCB, FCME, MEXU), 1284 (FCME, IEB, MEXU, MO), $1287 b$ (IEB), 2037 (FCME, IEB, MEXU, MO), s. n. (IEB, MEXU); Mazatlán, sobre la carretera federal a Acapulco $\left(17^{\circ} 26^{\prime} 06^{\prime} \mathrm{N}\right.$, 99²8'22”O), C.A. Durán 124 (ENCB, FCME); Salto Valadéz (17²7'20”N, 99²8'10”O), H. Kruse 1979 (FCME, MEXU), 2021 (FCME, IEB, MEXU, MO), 2719 (FCME, MEXU, MO); Tierras Prietas (17³6'03'N, 99`31'59'O), J. Maldonado 1002 (FCME, MEXU). Mpio. Coahuayutla de José María Izazaga: Amatepec, $3.7 \mathrm{~km}$ al SE (18 14'31'N, 101³7'13”O), J. Calónico 14372 (FCME, HUMO). Mpio. Coyuca de Benítez: $4 \mathrm{~km}$ al SE de Coyuca (16 $54^{\prime} 15^{\prime \prime}$ N, 99 58'00”O), A. Aquino 97 (FCME); El Camalote, Laguna de Mitla $\left(17^{\circ} 03^{\prime} 16^{\prime}\right.$ N, $\left.100^{\circ} 17^{\prime} 47^{\prime \prime O}\right)$, L. Lozada 778 (FCME); isla La Pelona (1657'00'N, 10001'03'O), R.M. Fonseca 296 (FCME); Idem, J.G. Coello 66 (FCME, IEB). Mpio. Coyuca de
Catalán: 2 km al O de Coyuca de Catalán (18¹8'54”N, 10042'16"O), L. Lozada 1548 (FCME); rio del Oro, a 8 km al SO de Coyuca de Catalán, sobre el camina a Ciudad Altamirano-Zihutanejo (18¹9'30'N, 10041'59”O), E.M. Martínez 660 (MEXU). Mpio. Cuautepec: $4 \mathrm{~km}$ antes de Cuautepec (1644'58”N, 9900'15”O), N. Diego 1983 (FCME, MEXU). Mpio. Eduardo Neri: $10 \mathrm{~km}$ al SE de Xochipala $\left(17^{\circ} 48^{\prime} 39^{\prime \prime} N\right.$, 99 $\left.38^{\prime} 45^{\prime \prime O}\right), \quad$ L. Soto 215 (FCME); 14 km de Mezcala, carretera México-Acapulco (1750'08’N, 99³3'56"O), A.R. López 33 (FCME); Amatitlán (17 $\left.51^{\prime} 55^{\prime \prime} \mathrm{N}, 99^{\circ} 45^{\prime} 38^{\prime \prime} \mathrm{O}\right), \quad$ R. Cruz 752 (FCME, MEXU); Ameyaltepec (17 $57^{\circ} 57^{\prime}$ N 99³0'28'O), A. Villa 802 (MEXU); barranca El Salado (1749'09”'N, 99³7'53”O), S. Peralta 147 (FCME); cerro Huiziltepec, orilla de La Laguna $\left(17^{\circ} 45^{\prime} 55^{\prime} \mathrm{N}\right.$, 99²8'29”'O), B. Ludlow 175 (FCME, IEB, MEXU); Mezcala, $6.5 \mathrm{~km}$ al O (17'53'02'N , 99'37'22'O), M. Luna 123 (FCME); puente Agustín Lorenzo, km 61 carretera Iguala-Chilpancingo, $100 \mathrm{~m}$ antes del puente (17 $50^{\circ}$ '13' $\mathrm{N}$, 994'8”O), N. González 32 (IEB, MEXU); puerto de Los Tepetates, $2 \mathrm{~km}$ al $\mathrm{N}$ de Amatitlán (17'52'37'N, 9945'39'O), R. Cruz 707 (FCME, MEXU); Xochipala,

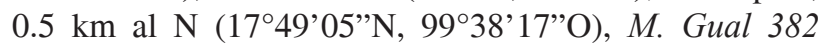
(FCME); Xochipala, 1 km al N (1749'05'N, 99³8'17'O), M. Gual 378 (FCME); Xochipala, $5.5 \mathrm{~km}$ al NE (1750'48’'N, 99³6'04”O), J.L. Contreras 399 (FCME, MEXU); Zumpango del Río (17³9'15’N, 99³1'40”O), H. Kruse 2451 (MEXU). Mpio. General Heliodoro Castillo: $0.9 \mathrm{~km}$ al $\mathrm{O}$ de Las Anonas $\left(17^{\circ} 52^{\prime} 15^{\prime} \mathrm{N}\right.$, 9953'15”O), J. Calónico 13341 (FCME); $3.6 \mathrm{~km}$ al N de Chapultepec $\left(17^{\circ} 50^{\prime} 50^{\prime \prime} \mathrm{N}, 99^{\circ} 57^{\prime} 04^{\prime} \mathrm{O}\right)$, J. Calónico $15498 b$ (FCME, IEB, MEXU); $9.3 \mathrm{~km}$ al SO de Tlacotepc (1744'10”'N, 99³0'00”'O), J. Calónico 11788 (FCME); Tlacotepec, rumbo a Puerto Amate (17 43'59'N, 10002'14”'O), J. Castrejón 1231 (ENCB, FCME, IEB). Mpio. Huamuxtitlán: $6 \mathrm{~km}$ SO de Huamuxtitlán hacia Tlaquiltepec $\left(17^{\circ} 48^{\prime} 08^{\prime \prime} \mathrm{N}, 98^{\circ} 33^{\prime} 35^{\prime \prime} \mathrm{O}\right)$, V. Aguilar 71 (FCME). Mpio. Huitzuco de los Figueroa: $2 \mathrm{~km}$ del Reparo (18²3'41'N, 99¹2'14'O), R.C. Bustamante 504 (HUMO); $3.5 \mathrm{~km}$ al $\mathrm{N}$ de San Francisco Ozomatlán (1755'34.62”'N, 99²0’20.48”O), A. Vargas 452 (FCME, MEXU). Mpio. Iguala de la Independencia: $1.5 \mathrm{~km}$ al $\mathrm{O}$ de La Joya $\left(18^{\circ} 15^{\prime} 52^{\prime}\right.$ N, 99³1'57’O), F. Terán 514 (FCME); $3 \mathrm{~km}$ al NE del poblado Platanillo (18 $25^{\prime} 08^{\prime}$ 'N, 99²9'24”O), S. Vázquez 218 (ENCB, FCME, IEB); 10 $\mathrm{km}$ al $\mathrm{N}$ de Iguala. La Cumbre, desviación al horno de miocroondas (18²0’40”N, 99³2’20”O), J.M. Díaz 240 (ENCB); $8 \mathrm{~km}$ al NO de Iguala, cerca de Mexicaltepec (18²0’42”N, 99³2'22”O), J.C. Soto 3962 (MEXU); cañón de la Mano, entre los Amates y El Naranjo, $10 \mathrm{~km}$ al N de Iguala, por el Ferrocarril (18²0’40”N, 99³2’20”O), C. Catalán 446 (IEB), 597 (IEB), 756 (MEXU); cerro con 
la antena de microondas Tuxpan al $\mathrm{N}$ de Iguala (18 22'07'N, 99³0'06'O), R.M. Fonseca 1747 (FCME); Iguala $\left(18^{\circ} 20^{\prime} 40^{\prime \prime} \mathrm{N}, 99^{\circ} 32^{\prime} 20^{\prime \prime} \mathrm{O}\right), \quad J$. Freeland 44 (MEXU); puente Campuzano (18²6'53”N , 99³5'08'O), F. Miranda 3953 (MEXU). Mpio. Ixcateopan de Cuauhtémoc: $2.5 \mathrm{~km}$ al $\mathrm{O}$ de Ixcateopán (18³0'19”N, 9947'35”O), A.G. Monzon s. n. (FCME). Mpio. José Azueta: $0.5 \mathrm{~km}$ antes de Playa Linda $\left(17^{\circ} 40^{\prime} 00^{\prime} \mathrm{N}\right.$, 101³9'00'O), G. Castillo 6682 (CH, MEXU, XAL); carretera a Ciudad Altamirano, desviación a La Vainilla (17²3'36”N, 101³3'38’O), M. Gual 469 (FCME); cerro

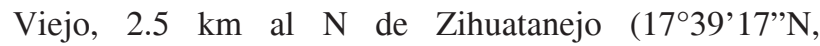
101'32'48'O), M. Gual 520 (FCME, IEB); punta Ixtapa (1740’00”N, 101³9’00”O), G. Castillo 6674 (XAL); Zihuatanejo (17³9'28’N, 101³5'37'O), L. Boege 1652 (MEXU). Mpio. Juan R. Escudero: Tierra Colorada, carretera a la presa General Figueroa (1707'40”N, 99³1'30"O), H. Kruse s. n. (FCME, MEXU). Mpio. La Unión de Isidoro Montes de Oca: $2.5 \mathrm{~km}$ al SO de Lagunillas, por el camino a La Majahua $\left(17^{\circ} 48^{\prime} 57^{\prime} \mathrm{N}\right.$, 10143'13”O), F.G. Lorea 4144 (ENCB, FCME, IEB, MEXU); $16 \mathrm{~km}$ al EN de Coyuquilla (18 $08^{\prime} 32^{\prime \prime} \mathrm{N}$, $102^{\circ} 21^{\prime} 37$ 'O), J.C. Soto 12519 (MEXU); Los Pájaritos, orilla del poblado La Unión (1758'54’N, 10148’12”O), E. Guizar 3059 (IEB, UAMIZ). Mpio. Leonardo Bravo: $2 \mathrm{~km}$ al SE de Xochipala (1746'00'N, 99³7'00'O), $S$. Peralta 55 (FCME); Atlixtac, $4 \mathrm{~km}$ al NO, hacia Chichihualco (17³8'15'N, 9940'37'O), F.G. Lorea s. $n$. (FCME). Mpio. Ometepec: $25 \mathrm{~km}$ al NO de Cuajinicuilapa, carretera Acapulco-Pinotepa Nacional (17 $28^{\prime} 16^{\prime} \mathrm{N}$, 99²2'14”O), E.M. Martínez 122 (ENCB, MEXU, MO). Mpio. Pilcaya: $9.8 \mathrm{~km}$ NO de Tetipac (18 43'56”N, 9940'55'O), R. Cruz 2219 (IEB); Cacahuamilpa (1840'57’N, 99³0’23”O), F. Miranda 1484 (MEXU). Mpio. Quechultenango: $1 \mathrm{~km}$ después de Coatomatitlán, dirección Colotlipa (17²3'52’'N, 9909'36”O), A. Nuñéz 90 (FCME, MEXU); 2 km al S de Quechultenango, camino deHerraduraa Tlayolapa $\left(17^{\circ} 23{ }^{\prime} 50.76\right.$ ”N, $99^{\circ} 15^{\prime} 10.38^{\prime}$ 'O), A. Nuñéz 1015 ((FCME, MEXU); proximidades a Quechultenango, $27 \mathrm{~km}$ al E de Chilpancingo (17²4'54'N, 99¹4'30"O), C. Tejeda s. n. (IEB), s. n. (IEB; MEXU). Mpio. San Marcos: $1 \mathrm{~km}$ del camino a Pesquería, Laguna de Tecomate (1643'04'N, 99²4'03'O), L. Lozada 1386 (ENCB, FCME, IEB, MEXU); Agua Zarca de la Peña (1658'07'N, 99³6'12”O), M.A. Gómez 194 (FCME, IEB); cañada al O de Agua Zarca (16 $58^{\prime} 07^{\prime}$ N, 99³6'12”O), E. Velázquez 637 (FCME, IEB, MEXU). Mpio. Tecpan de Galeana: cerro Japón, $1 \mathrm{~km}$ al S de El Carrizal $\left(17^{\circ} 11^{\prime} 26\right.$ 'N, 10043'43”O), F.G. Lorea 5158 (FCME, IEB, MEXU); El Pusulmiche, $3 \mathrm{~km}$ del entronque de la brecha a Corinto con la carretera Tecpan de GaleanaZihuatanejo (17 $18^{\prime} 46^{\prime \prime} \mathrm{N}, 100^{\circ} 35^{\prime} 53$ 'O), P. Tenorio 1333
(ENCB, MEXU, MO). Mpio. Tepecoacuilco de Trujano: entre Oapan y Ameyaltepec (1757'35'N, 99²8'29'O), J. Amith 444 (FCME, IEB, MEXU). Mpio. Tixtla de Guerrero: cerro a la orilla de la laguna de Tixtla (17³7'30’'N, 99²9’30”O), B. Ludlow 217 (FCME, MEXU), 295 (FCME, IEB); Tixtla (17³4’28’'N, 99²3'50”O), B. Ludlow 106 (FCME, IEB), 115 (FCME, MEXU); Tixtla, cerro La Virgen de Guadalupe (17²7'00'”N, 10009'00'O), B. Ludlow 140, 264 (FCME, MEXU), 153 (FCME, IEB, MEXU). Mpio. Tlapa de Comonfort: $500 \mathrm{~m}$ al $\mathrm{N}$ sobre una barranca del río Salado, $4 \mathrm{~km}$ al E de Tlapa (17³5'37’N, 98³1'36”O), A. García 7473 (MEXU); $1 \mathrm{~km}$ al $\mathrm{N}$ de San Miguel Axoxuca (17³2'00”N, 9841'00"O), C.A. Durán 67 (ENCB, FCME, IEB, MEXU); $8 \mathrm{~km}$ al SO de Tlapa de Comonfort (17³2'00’'N, 99³9'00'O), C.A. Durán 66 (ENCB, FCME, IEB, MEXU); $12 \mathrm{~km}$ de Tlapa hacia Chilapa (17³2’22”N, 98³9’02”O), G. Campos 586 (FCME). Mpio. Xalpatláhuac: $7 \mathrm{~km}$ al NO de Atlamajalcingo del Monte (17³1'00”'N, 98³6'00”O), C.A. Durán 61 (ENCB, FCME, IEB, MEXU). Mpio. Xochihuehuetlán: cañada Tecoapano, lado NE del cerro Xilotán (1758'21'N, 99²8'18”O), E. Moreno 1071 (FCME). Mpio.Zirándaro: $4 \mathrm{~km}$ antes de San Antonio, camino que va de El Timón a La Parota (18²6'6”N, 1019'30”O), R.E. González 271 (FCME, IEB, MEXU); camino a Zirándaro-Guayamea en El Capire, $28 \mathrm{~km}$ al SO de Zirándaro (18²7'12'N, $\left.101^{\circ} 18^{\prime} 22^{\prime \prime} \mathrm{O}\right)$, J.C. Soto 4346 (ENCB, MEXU); La Piedra, $27 \mathrm{~km}$ al NE de Guayameo (18¹6’00”N, 10109'00”O), J.C. Soto 688 (MEXU, XAL).

\section{Comentarios taxonómicos}

Especie ampliamente distribuida en Guerrero en el bosque tropical caducifolio, bosque de galería, bosque de Quercus y vegetación secundaria derivada de estos tipos de vegetación, desde el nivel del mar hasta $1620 \mathrm{~m}$ snm. La floración y fructificación se presentan con mayor frecuencia de mayo a diciembre. Esta especie tiene frutos comestibles, se usa como árbol de sombra y aparentemente presenta propiedades desinflamatorias. En México es una especie con amplia distribución en la vertiente del Golfo desde Tamaulipas hasta la península de Yucatán; por el lado del Pacífico se le registra desde Sonora hasta Chiapas, además de Chihuahua, Durango, Guanajuato, Morelos, Puebla, Querétaro, San Luis Potosí y Zacatecas; fuera del país se localiza en Belice y Guatemala hasta Costa Rica.

Carvajal y Peña-Pinela (1997) señalan que la variación que exhiben los individuos de esta especie es alta y sugieren la posible existencia de 2 o más entidades, que requieren de un análisis más cuidadoso para su separación. Posteriormente, Carvajal et al. (2001) proponen 2 
subespecies con fundamento en la forma de la base de la lámina, la longitud y tipo de pubescencia del pecíolo (subsp. cotinifolia y subsp. myxaefolia (Kunth) Carvajal). Sin embargo, el material de Guerrero presenta gran variación en estos caracteres aparentemente diagnósticos, lo que no permite separarlas con claridad; una situación similar ha sido encontrada en el estado de Morelos por PiedraMalagón et al. (2006). Por lo anterior, no se reconocieron estas subespecies en el presente trabajo.

4. Ficus crocata (Miq.) Miq. Ann. Mus. Bot. LugdunoBatavum 3: 297, 1867. F. hemsleyana Standl. Contr. U. S. Nat. Herb. 20(1): 29. 1917. (Fig. 1C, 4).

Nombres comunes. Amate, amate prieto, ceiba.

Árboles hemiepífitos o estranguladores, perennifolios, de 10-30 m de alto, tallos monopódicos, con oquedades entre las raíces aéreas y contrafuertes definidos, corteza grisácea, exudado blanco y abundante, blanco rosado al oxidarse, con copa amplia y redondeada, verde oscuro. Yema foliar terminal de 13-19 mm de largo, 4-7.5 mm de ancho, parda en material seco, ligeramente pubescente, con tricomas grisáceos o amarillos; entrenudos de (0.3) 0.8-2.5 (3.5) $\mathrm{mm}$ de largo, 4.5-12 $\mathrm{mm}$ de ancho, pardos o grisáceos, a veces estriados, glabros. Pecíolo de 1935 (42) $\mathrm{mm}$ de largo, (16) 20-30 mm de ancho, pardo o pardo verde, estriados, ligeramente pubescentes, a veces acanalados por el haz; lámina foliar de (4) 7.2-10.3 (17.2) cm de largo, (2.6) 3.9-7.2 cm de ancho, 1.5-1.8 (2.3) veces más larga que ancha, elíptica, ovada u obovada, parda a grisáceo amarillenta, coriácea; base cuneada, truncada o redondeada, en ocasiones con 1 glándula negra en la inserción del pecíolo por el envés; ápice redondeado o ligeramente acuminado; haz verde pardo, glabro; envés verde pardo, glabro a ligeramente pubescente, venas secundarias amarillas a pardas, en ocasiones ligeramente pardo rojizas, 7 a 11 pares, el primero opuesto y los demás alternos. Siconos de 1.1-1.9 cm de largo, 1.2-2.7 cm de diámetro, esferoides o piriformes, verdes con máculas rojas o amarillas en material fresco, pardos con máculas oscuras en material seco, pilósulos, con las flores blanco rojizas; ostíolo de 3-4.5 $\mathrm{mm}$ de diámetro, rodeado por un anillo engrosado y oclusionado por 3 escamas pardas; brácteas basales de 3-7 mm de largo, 3-7 mm de ancho, verdes en fresco, pardo verdes en seco, con el ápice redondeado o agudo, 3 o 4 partidas, caedizas o raramente persistentes, glabras o pilosas por el haz y glabras por el envés; pedúnculo de 7-14.5 mm de largo, verde o pardo, glabro o piloso.

\section{Resumen taxonómico}

Material examinado. Mpio. Acapulco de Juárez: 2.5 km al O de puerto Marqués (1653'53'N, 9952’23”O), W. López 548 (MEXU); Acapulco (1651'47'N, 98 53'47”O), E.A. Palmer 373 (F, MEXU); Idem, W. López 1095 (MEXU); Barra Vieja, camino a Pinotepa Nacional (1641'38'N, 99³8'13'O), L. Boege 1867 (MEXU); viveros El Huayacán, La Poza (1646'27’N, 99³6'06”O), W. López 810 (MEXU), 1096 (MEXU), 1360 (MEXU); isla Roqueta (1653'53’N, 9952’23”O), J. Mancilla 28 (FCME); La Poza, al SO de Viveros El Huayacán (1651'00”N, 9953'00”O), W. López 1092 (MEXU, XAL); parque recreativo Papagayo, avenida Miguel Alemán Acapulco (1646’28'N, 99³6'05'O), J.I. Calzada 17709,17681 (MEXU); costera de Acapulco (1651'47'N, 98॰53’47'O), W. López 1094 (FCME, MEXU, UAMIZ). Mpio. Ahuacuotzingo: Ajuatetla, reserva campesina $\left(17^{\circ} 37^{\prime} 06^{\prime \prime} \mathrm{N}, 99^{\circ} 07^{\prime} 33^{\prime}\right.$ O) $)$ N. Diego 7349 (ENCB, FCME, IEB, MEXU). Mpio. Alpoyeca: 1 km al E de Tecoyo (17³5'20’'N, 98²9'29'O), J. Calónico 517 (FCME). Mpio. Atlixtac: $0.4 \mathrm{~km}$ al S de Petatlán (17³4’36”N, 9859'29”O), R. Redonda 191 (FCME); Petatlán, $0.5 \mathrm{~km}$ al S (17³4’30”N, 9959'32”O), L. Mendizabal 61 (FCME). Mpio. Atoyac de Álvarez: Rincón de Las Parotas, $9 \mathrm{~km}$ al NE de Atoyac de Alvaréz, sobre el río La Parota $\left(17^{\circ} 14^{\prime} 00^{\prime \prime} \mathrm{N}, 100^{\circ} 24^{\prime} 00^{\prime} \mathrm{O}\right)$, C.A. Durán 115 (ENCB, FCME, IEB, MEXU). Mpio. Buenavista de Cuéllar: $6 \mathrm{~km}$ al $\mathrm{N}$ de Buenavista de Cuellar, carretera federal Cuernavaca-Iguala (18³7'52’N, 99²4'09”O), C.A. Durán 92 (ENCB, FCME, IEB, MEXU), 96 (FCME, IEB, MEXU). Mpio. Chilpancingo de los Bravo: $1 \mathrm{~km}$ al O de Balsas Norte (18³5'00”'N, 9946’10”O), M. Blanco 541 (ENCB, MEXU, XAL); $5 \mathrm{~km}$ antes de Agua de Obispo, carretera México-Acapulco (17²8'16”N, 99²2'14'O), A.R. López 83 (FCME, MEXU); 14 km

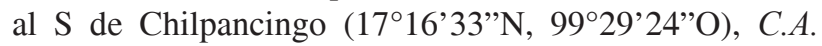
Durán 121 (ENCB, FCME, IEB, MEXU); $21 \mathrm{~km}$ al O de Chilpancingo, camino a Omiltemi (17³3'14'”N, 99³9'59”O), E.M. Martínez 207 (ENCB, MO); Agua de Obispo, Barranca del Cuarenta (17 $\left.{ }^{\circ} 18^{\prime} 50^{\prime \prime} \mathrm{N}, 9^{\circ} 28^{\prime} 00^{\prime \prime O}\right)$, H. Kruse 1281 (FCME, IEB, MEXU); Rincón de la Vía (17'17'15”N, 99²8'55"O), H. Kruse 1282 (FCME, MEXU); Rincón Viejo (17¹7’40”N, 99³0’00”O), $H$. Kruse 1073 (FCME, MEXU); río La Hamaca, al SE de Zoyaltepec (17¹9'30'N, 99³2'44”O), L.C. Rodríguez 379 (FCME, IEB, MEXU); cerro "Culebreado" al O de Chilpancingo (17³3'14”N, 99³0'13”O), J. Chavelas 1789 (ENCB, INIF). Mpio. Coahuayutla de José María Izazaga: El Maguey, $0.87 \mathrm{~km}$ al $\mathrm{S}$ de Coahuayutla de Guerrero (18²4’28”N, 101³5’41”O), J. Calónico 14907 (FCME, HUMO). Mpio. Coyuca de Benítez: isla La Pelona (16 57'00'N, 10001'03'O), C. Verduzco 291 (FCME). Mpio. Coyuca de Catalán: $2 \mathrm{~km}$ al SO de San Isidro (17 52 '20”'N, $101^{\circ} 06^{\prime} 41^{\prime}$ 'O), L. Meza s. n. (FCME); 
Palo Nuevo, $82 \mathrm{~km}$ al SO de Ciudad Altamirano, carretera a Zihuatanejo (1801'39'”N, 101 ${ }^{\circ} 06^{\prime} 13$ 'O), J.C. Soto 4986 (HUMO, IEB, MEXU); Placeres del Oro (18 $14^{\circ} 10^{\prime} \mathrm{N}$, 10054'3"O), J.C. Soto 3888 (IEB, MEXU). Mpio. Eduardo Neri: $10 \mathrm{~km}$ al SO de Xochipala (17 $48^{\prime} 40^{\prime \prime} \mathrm{N}$, 99³8'45"O), J.C. Soto 8232 (IEB, MEXU); Amatitlán (17'51'55'N, 9945'38'O), R. Cruz 847 (FCME). Mpio. Iguala de la Independencia: $15 \mathrm{~km}$ al $\mathrm{S}$ de Iguala, sobre la carretera federal a Chilpancingo $\left(18^{\circ} 11^{\prime} 38^{\prime \prime} \mathrm{N}\right.$, 99³2’49”O), N. González 30 (IEB). Mpio. José Azueta: El Sandial, $2.7 \mathrm{~km}$ al N (1747'11'N, 101³8'25'O), A. Díaz 185 (ENCB, FCME, IEB, MEXU); isla Ixtapa, Zihuatanejo (17 $39^{\prime} 28^{\prime}$ N, $101^{\circ} 35^{\prime} 37^{\prime}$ O), M. Pérez s. $n$. (MEXU); Las Higueritas, $28 \mathrm{~km}$ al NE de La Salitrera, carretera Zihuatanejo-Ciudad Altamirano (17³8'39'N, 101³3'03”O), J.C. Soto 4513 (IEB, MEXU); punta Ixtapa (1740'0”N, 101³9'0”O), G. Castillo 6673 (XAL). Mpio. Mochitlán: sin localidad (17¹8'50”N, 99²8'10”O), H. Kruse s. n. (FCME, MEXU, MO). Mpio. Ometepec: arroyo Huacapa, camino a Igualapa (16 $44^{\prime} 17^{\prime}$ N , 98²8’38”O), R.M. Fonseca 1124 (ENCB, FCME, IEB). Mpio. Pilcaya: Tetipac, $9.9 \mathrm{~km}$ al NO (18 $43^{\prime} 56^{\prime \prime} \mathrm{N}$, 9940'56"O), R. Cruz 2217 (FCME, HUMO). Mpio. Quechultenango: proximidades de Quechultenango, 27 km al O de Chilpancingo (17²4'54”N, 99¹4'30”O), $C$. Tejeda s. $n$. (IEB, MEXU). Mpio. Taxco de Alarcón: cerca de Taxco Viejo y Tlapulco (18²9'03'N, 99³5'09'O), R. Bonilla s. n. (ENCB); Piedras Negras, $12.9 \mathrm{~km}$ al SE (18³7'27’N, 99³1'56”O), J. Calónico 10072 (FCME, HUMO); Tehuilotepec (18`33'07.30'”, 99³4'52”O), $M$. Martínez s. n. (F). Mpio. Teloloapan: Las Ceibitas, km 96 carretera a Iguala $\left(18^{\circ} 23^{\prime} 00^{\prime \prime} \mathrm{N}, 100^{\circ} 05^{\prime} 00^{\prime} \mathrm{O}\right)$, H.H. Iltis 28702 (ENCB, F, MEXU). Mpio. Tixtla de Guerrero: La Estacada (17³4'29'N, 99²3'50'O), N. Diego 7051 (FCME, IEB, MEXU). Mpio. Tlapa de Comonfort: río Tlapaneco, rumbo a Chilapa de Álvarez (17³2'00”N, 98³8'00"O), C.A. Durán 63 (FCME, IEB, MEXU). Mpio. Xochihuehuetlán: cañada Axiococa, lado NE del cerro Xilotzin (1759'07'N, 98²9'29'O), E. Moreno 897 (FCME), 973 (FCME), 1029 (FCME, HUAP). Mpio. Zirándaro: $2 \mathrm{~km}$ al $\mathrm{N}$ de Guayameo $\left(18^{\circ} 18^{\prime} 00^{\prime} \mathrm{N}\right.$, $101^{\circ} 15^{\prime} 42^{\prime \prime O}$ ), J.C. Soto 4373 (IEB, MEXU). Mpio. no determinado: sierra Madre, E. Langlassé 1001 (MEXU).

\section{Comentarios taxonómicos}

Árboles que habitan principalmente en la vegetación de galería asociada al bosque tropical caducifolio y bosque tropical subcaducifolio, así como en el bosque de Quercus y vegetación secundaria derivada de estas comunidades vegetales, entre 350 y 1660 m snm. La floración y fructificación de $F$. crocata se produce durante todo el año. Esta especie se distribuye en nuestro país desde Sonora hasta Chiapas, además de Morelos, Puebla Veracruz y la península de Yucatán; fuera de México se encuentra en Centroamérica y hacia el sur hasta Brasil y Perú. Berg (1989) la consideró parte del complejo taxonómico de $F$. trigonata L., que incluye entre otras especies $F$. goldmanii Standl., F. morazaniana W.C. Burger y F. gommelleira Kunth et C.D. Bouché.

5. Ficus insipida Willd. Sp. Pl. (quarto ed.) 4: 1143. 1806. F. glabrata Kunth. Nov. Gen. Sp. (quarto ed.) 2: 47, 1817; F. segoviae Miq. Ann. Mus. Bot. Lugduno-Batavum 3: 300, 1867; F. radulina S. Watson. Proc. Am. Acad. 26: 151, 1891. (Fig. 1D).

Nombres comunes. Amate blanco, ceiba, ceiba colorada, saiba blanca.

Árboles perennifolios de 4-20 m de alto, tallos monopódicos, contrafuertes definidos, fuste recto, corteza lisa, grisácea, con exudado blanco, abundante, con una copa densa y redondeada, verde pálida. Yema foliar terminal de 21.5-65 $\mathrm{mm}$ de largo, 1.7-5 mm de ancho, parda o verde oscuro, glabra o pilosa en la base; entrenudos de (6) $13-52 \mathrm{~mm}$ de largo, 4-7.5 mm de ancho, pardos, amarillos o grises, lisos, glabros o raramente con tricomas blancos. Pecíolo de (5) 8-40 (69) mm de largo, 1.2-3.5 mm de ancho, pardo verde o verde amarillo, estriados, glabros; lámina foliar de (3.8) 5-22 cm de largo, (1.4)1.7-5.5 (7.9) cm de ancho, 2.7-3.6 veces más larga que ancha, elíptico lanceolada, verde amarilla o verde opaca, coriácea; base atenuada a ligeramente truncada; ápice acuminado, en algunas ocasiones apiculado; haz verde, glabro o en raras ocasiones seríceo; envés verde amarillento, glabro o seríceo, venas secundarias amarillas o verde amarillas, prominentes, 13 a 21 pares, opuestos en el primer y segundo par, los demás alternos. Siconos rara vez geminados (C.A. Durán 122), de 15-30 mm de largo, 15-25 (31) mm de diámetro, esferoides, verdes o amarillos, con máculas circulares amarillas o blancas en material fresco, verdes o pardos con máculas amarillas o pardas en material seco, glabros, flores de color rojo en fresco; ostíolo de 1.7-3 mm de diámetro; brácteas basales de 1-2 mm de largo, 2.5-5 mm de ancho, pardas, con el ápice agudo, caducas, glabras; pedúnculo de 3-11 mm de largo, 1.7-5 mm de ancho, verde opaco o pardo, glabro a ligeramente piloso.

\section{Resumen taxonómico}

Material examinado. Mpio. Acapulco de Juárez: $2 \mathrm{~km}$ al O de Puerto Marqués (1653‘53“N, 9952‘13“O), $W$. López 1118, 1155 (ENCB, MEXU, XAL); Acapulco, cerca del Puerto aéreo $\left(16^{\circ} 51^{\prime} 47^{\prime} \mathrm{N}, 98^{\circ} 53^{\circ} 47^{\prime \prime} \mathrm{O}\right), L$. 
Boege 1888 (MEXU); ejido El Manolito, laguna de Tres Palos (17²0‘45“N, 99`33‘38“'O), N. Diego 3757 (FCME, MEXU); Parque Nacional El Veladero, Santa Cecilia (16 $51^{\circ} 0^{\circ}$ “N, 99॰50‘00“O), N. Noriega 83 (ENCB, FCME); Parque Nacional El Veladero (165' $\left.53^{\prime \prime N} \mathrm{~N}, 99^{\circ} 52^{\prime} 13^{\prime \prime} \mathrm{O}\right)$, N. Noriega 758 (MEXU); parque recreativo Papagayo, sobre avenida Miguel Alemán-Acapulco (1646'28“N, 99³6“05“O), J.I. Calzada 17710 (MEXU); río de Sabana,

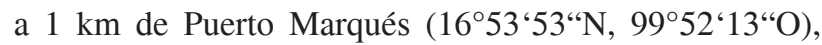
R. Gutiérrez 90 (FCME). Mpio. Arcelia: cañada Limón, $5.3 \mathrm{~km}$ al SO del campamento minero de Campo Morado (18 $\left.12^{\prime} 27^{\prime} \mathrm{N}, 100^{\circ} 07^{\prime} 45^{\prime} \mathrm{O}\right)$, R. Cruz 6083 (FCME); Campo Morado and hills above town (17 $34^{\prime} 00^{\prime \prime} \mathrm{N}$, 100¹0'00”O), J.S. Miller 2899 (MO). Mpio. Atenango del Río: $1 \mathrm{~km}$ al NE de Atlapa (18¹4'27'N, 9902'59'O), O. Delgado 1194 (FCME). Mpio. Atoyac de Álvarez: $18 \mathrm{~km}$ al S de El Paraíso, carretera El Paraíso-Atoyac (17³3'82”N, 100²8'08”O), C.A. Durán 113 (IEB, MEXU); El Salto, $3 \mathrm{~km}$ de Mexcatepec (17¹6'09'N, 100²5'00”O), N. Turrubiante s. n. (FCME); Rincón de Las Parotas, $9 \mathrm{~km}$ al NE de Atoyac de Alvaréz, sobre el río La Parota $\left(17^{\circ} 14^{\prime} 00^{\prime} N\right.$, $100^{\circ} 23^{\prime} 00^{\prime}$ O), C.A. Durán 116 (FCME, MEXU). Mpio. Buenavista de Cuéllar: Cieneguillas, $11 \mathrm{~km}$ al SO de Buenavista $\left(18^{\circ} 24^{\prime} 36^{\prime \prime} \mathrm{N}\right.$, 99²8'36"O), J.C. Soto 8747 (IEB, MEXU). Mpio. Chilpancingo de los Bravo: $1 \mathrm{~km}$ al $\mathrm{S}$ de Zoyatepec, camino a Ocotito de los Bravos (17²9'29'N , 99³3'20”O), E.M. Martínez 2610 (ENCB, MEXU); Barranca El Platanar (17 $\left.17^{\prime} 55^{\prime \prime} \mathrm{N}, 99^{\circ} 33^{\prime} 40^{\prime \prime O}\right)$, C. Verduzco 483

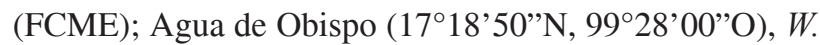
López 868 (MEXU); camino a la estación de microondas El Alquitrán (17²6'40”N, 99²9'04”O), L. Lozada 2348 (FCME, MEXU); Mazatlán, sobre la carretera federal que va a Acapulco $\left(17^{\circ} 26^{\prime} 06^{\prime \prime}\right.$, 99²8'22”O), C.A. Durán 122 (FCME, MEXU), 123 (ENCB, IEB); Rincón de la Vía (17 ${ }^{\circ} 17^{\prime} 15^{\prime}$ N, $99^{\circ} 28^{\prime} 55^{\prime}$ 'O), H. Kruse 442 (FCME, MEXU); río Apetlaca, Acahuizotla (17²2'59”N, 99²7'05”O), H. Flores 169 (FCME, MEXU); río Azinyehualco, al N de Zoyaltepec (17²0'45'N, 99³3'38'O), L.C. Rodríguez 382 (FCME, IEB); río La Hamaca, al SE de Zoyaltepec $\left(17^{\circ} 01^{\prime} 30^{\prime}\right.$ N, $100^{\circ} 05^{\prime} 30^{\prime}$ 'O), L.C. Rodríguez 373 (IEB, MEXU); Tlacotepec, a $5 \mathrm{~km}$ al NE después de Chilpancingo (1749'12'N, 9956'18'O), R. Cruz 3842 (FCME). Mpio. Coahuayutla de José María Izazaga: El Aguacate, $3.9 \mathrm{~km}$ al S (1808'16”N, 101 27'32”O), J. Calónico 15870 (FCME); La Vainilla, $2.8 \mathrm{~km}$ al $\mathrm{N}$ (18`11'29”N, 101²9'46”O), J. Calónico 15165 (FCME, MEXU). Mpio. Copalillo: Tlalcozotitlán, Mezquitlán, Copalillo (19॰86'00”N, 99²3'00”O), T. Rodríguez 132 (HUMO). Mpio. Coyuca de Benítez: $8 \mathrm{~km}$ al SO de El Cundancito (18 $\left.01^{\prime} 22^{\prime \prime} N, 101^{\circ} 07^{\prime} 27^{\prime \prime O}\right)$, J.C. Soto 8643 (MEXU); $100 \mathrm{~m}$ de la entrada campo de tiro (16 $54^{\prime} 11^{\prime \prime} \mathrm{N}$,
9958'3”O), A. Aquino 77 (FCME); arroyo El Zapote, laguna de Mitla (1708'54”N, 10040'33”O), L. Lozada 553 (ENCB, FCME). Mpio. Coyuca de Catalán: 13 km al S de Placeres del Oro, carretera Ciudad AltamiranoZihuatanejo (1808'49'N, 10054'38'O), J.C. Soto 2325 (ENCB, MEXU). Mpio. Eduardo Neri: $6 \mathrm{~km}$ adelante de la desviación, por la brecha que va a Axoxohualco (1740’49”'N, 99³0’46”O), M. Blanco 581 (ENCB, MEXU, XAL); Axaxacoalco, $8 \mathrm{~km}$ al S (17 $45^{\prime} 50^{\prime \prime} \mathrm{N}$, 99²8'41'O), S. Valencia 1214 (FCME, MEXU); El Platanal, $4 \mathrm{~km}$ al NE, desviación a Huitziltepec (1742'13'N, 99³5’30”O), S. Valencia 1031 (FCME). Mpio. Florencio Villareal: aproximadamente $2 \mathrm{~km} \mathrm{~N}$ de Chautengo (16³8'57'N, 9905'28'O), R.M. Fonseca 1639 (FCME, IEB, MEXU). Mpio. Huamuxtitlán: 4.5

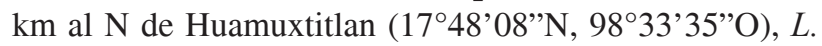
Meza s. $n$. (FCME); ladera E de un cerro, $3.5 \mathrm{~km}$ al NE de Huamuxtitlán $\left(17^{\circ} 48^{\prime} 08^{\prime}\right.$ 'N, 98`33'35'O), J.L. Contreras 1035 (FCME). Mpio. Iguala de la Independencia: cañón de la Mano, entre los Amates y El Naranjo, $10 \mathrm{~km}$ al N de Iguala por el Ferrocarril (18²3'54”N, 99³2'06”O), C. Catalán 213 (IEB, MEXU); Idem, F. Terán 30 (FCME, MO); Iguala de la Independencia, $5 \mathrm{~km}$ al $\mathrm{N}$, carretera a Taxco (18²2'49”'N, 99³1'45”O), J. Rzedowski 31875 (ENCB); Iguala, SO de la Cabaña (18²0’40”N, 99³2’20”O), J. Freeland 35 (MEXU). Mpio. José Azueta: $3 \mathrm{~km}$ al N de vallecitos de Zaragoza (1755’33'N, 101¹9'25'O), J.C. Soto 12489 (MEXU); $38 \mathrm{~km}$ al NE de Zihuatenejo, por la carretera Zihuatanejo-Ciudad Altamirano (17 $50^{\circ} 33^{\prime}$ N 10149'25”O), P. Tenorio 400 (ENCB, MEXU); Laguna Playa Blanca $\left(17^{\circ} 32^{\prime} 06^{\prime \prime N}, 1^{\circ} 1^{\circ} 25^{\prime} 51^{\prime \prime O}\right)$, G. Segura 39 (FCME); Paso de Vallecitos, $2 \mathrm{~km}$ al NO de Vallecitos de Zaragoza (1755'18’N, 101 '19'12'”O), J.C. Soto 11634 (IEB, MEXU); playa La Ropa a Zihuatanejo (1740'00”'N, 101³4'00'O), G. Castillo 6540 (XAL). Mpio. Juan R. Escudero: along gravel road between Tierra Colorada and Xalpatlahuac, between Tierra Colorado and bridge over Rio Comitlan (1708'32.18'N, 99²3'34.02'O), T.B. Croat 45749 (MO); Tierra Colorada (1709'56”N, 99³1'35'O), H. Kruse 1285 (FCME, MEXU), s. n. (FCME, IEB, MEXU). Mpio. La Unión de Isidoro Montes de Oca: 17 km NE de El Bálsamo (1805'11'N, 10055'33”O), T.P. Ramamoorthy 4303 (MEXU); $57 \mathrm{~km}$ al NE de Vallecitos y $2.5 \mathrm{~km}$ al E de Palo Nuevo (18²'44”N, 101'3'42”O), V.W. Steinmann 4925 (MEXU); El Zapotillo, camino a la gruta, $2.5 \mathrm{~km}$ al E de La Unión (1759'32'N, 10147'09'O), E. Guizar 3490 (CH); vallecitos de San Miguel (1758'32'N, 101³6'2”O), G.B. Hinton 10275 (ENCB). Mpio. Leonardo Bravo: $2 \mathrm{~km}$ al NO de Yextla $\left(17^{\circ} 37^{\prime} 25^{\prime}\right.$ N, 9956’42”O), J. Calónico 8245 b (ENCB, FCME, IEB, MEXU); $9.7 \mathrm{~km}$ al NO de Tres Caminos (17 $37^{\prime} 25^{\prime}$ 'N, 9956’35”O), B. González 1807 (FCME, IEB, MEXU); 
$11.6 \mathrm{~km}$ al S de Tres Caminos (17²7'48’N $\left.99^{\circ} 52^{\prime} 6^{\prime \prime} \mathrm{O}\right)$, J. Calónico 8810 (ENCB, FCME, IEB). Mpio. San Marcos: río La Estancia, cerca de la carretera AcapulcoPinotepa (1646'49'N, 99²7’25”O), R.M. Fonseca 1993 (FCME, IEB, MEXU); río El Cortéz, cerca de la carretera Acapulco-Pinotepa (1646’46”N, 99³0'40”O), R.M. Fonseca 1886 (ENCB, FCME, MEXU), 1890 (FCME). Mpio. San Miguel Totolapan: $2 \mathrm{~km}$ al SO de San Miguel Totolapan (1809'34'N, 100²3'32'O), $O$. García 80 (FCME). Mpio. Taxco de Alarcón: $13 \mathrm{~km}$ al S de Taxco (18²6'06”N, 99³6'11'O), J. Calónico 9392 (FCME); South of Taxco (18 33'14'N, 99 36'17'O), O.M. Clark 7102 (MO). Mpio. Tecpan de Galeana: El Pusulmiche, $3 \mathrm{~km}$ del entronque de la brecha a Corinto con la carretera Tecpan de Galeana-Zihuatanejo (17²'31”N, 100³5'53”O), P. Tenorio 1332 (ENCB, MEXU, MO, XAL). Mpio. Teloloapan: Las Ceibitas (18²3'00”N, 10005'00”O), H.H. Iltis 28703 (ENCB, F, MEXU). Mpio. Tepecoacuilco de Trujano: San Marcos Oacacingo (1757'33”N, 99²7’40”O), J. Amith 402 (IEB, MEXU). Mpio. Tlapa de Comonfort: $1 \mathrm{~km}$ al $\mathrm{NO}$ de Tlapa de Comonfort, sobre el río Tlapaneco (17³2'00’'N, 98³8'00"O), C.A. Durán 62 (ENCB, FCME, MEXU), 65 (ENCB, FCME, IEB). Mpio. Xochihuehetlán: 2 km NO de Xochihuehuetlán (1754'15'N, 98²9'17'O), J.I. Calzada 16095 (FCME, MEXU, UAMIZ); cañada Tecoapano, lado NE del cerro Xilotzin (1758’21’”N, 98 $28^{\circ} 18^{\prime}$ 'O), E. Moreno 1041 (FCME). Mpio. No determinado: brecha a Playa del Sol $5 \mathrm{~km}$ al NO de la Huacana, E.M. Martínez 478 (MEXU, UAMIZ); Temisco, barranca below one mille, Y. Mejía 8833 (F, MO).

\section{Comentarios taxonómicos}

Especie cuyos individuos habitan cerca de cuerpos de agua estacionales o permanentes asociados a distintas asociaciones vegetales como el bosque tropical caducifolio o subcaducifolio, vegetación secundaria derivada de estos coberturas vegetales o pastizales, desde el nivel del mar hasta $1600 \mathrm{~m}$ snm. La floración y fructificación se presentan durante todo el año. La especie se distribuye desde Sonora hasta Chiapas y por el lado de la vertiente del golfo de México desde Tamaulipas hasta la península de Yucatán; en el centro del país se encuentra en Durango, Morelos, Puebla, Querétaro y San Luis Potosí; fuera de México se localiza en Centroamérica y Sudamérica (hasta Argentina). Berg et al. (1984) y Carvajal (1995) proponen subespecies para $F$. insipida que se distinguen por ser glabras o pilosas en las ramillas de la estación y en esta última condición por el tipo de tricomas que presentan (subsp. insipida, subsp. radulina Carvajal, subsp. scabra Berg y subsp. segoviae Carvajal). Estas categorías no se usaron en el presente trabajo, pues los caracteres propuestos no son consistentes para permitir una separación clara del material de Guerrero. Una ilustración de la especie se encuentra en Ibarra-Manríquez y Wendt (1992) y en Berg y Villavicencio (2004).

6. Ficus lapathifolia (Liebm.) Miq. Ann. Mus. Bot. Lugduno-Batavum 3: 297. 1867. (Fig. 1D).

Árboles perennifolios de 25-35 m de alto, con tallos rectos, con contrafuertes, corteza pardo grisácea y exudado blanco, pardo pálido al oxidarse, escaso en la corteza, pero abundante en madera y ramas juveniles, con una copa abierta o densa, redondeada, verde pálida a opaca. Yema foliar terminal de $40 \mathrm{~mm}$ de largo, $9 \mathrm{~mm}$ de ancho, verde, glabra; entrenudos de 10-20 mm de largo, 4-6 mm de ancho, pardo negruzcos, lisos, raramente escamosos o ligeramente estriados, glabrescentes. Pecíolo de 30$35 \mathrm{~mm}$ de largo, 3-4 mm de ancho, pardo verdoso, liso, ligeramente acanalado por el haz, glabrescente; lámina foliar de 22-24 cm de largo, 14-15 cm de ancho, 1.5-1.6 veces más larga que ancha, elíptica, verde opaco, coriácea; base anchamente redondeada u obtusa; ápice obtuso; haz pardo verdoso ligeramente escabroso al tacto, glabrescente; envés pardo verdoso, pubescente, ligeramente escabroso, venas secundarias 14 a 16 pares, el primer o segundo par opuestos, los demás alternos. Siconos de 2-2.5 cm de largo y ancho, esféricos, verdes en fresco, pardos en material seco, pubescentes, ligeramente escabrosos; ostíolo de 1-2 $\mathrm{mm}$ de largo y 1.5-2 $\mathrm{mm}$ de ancho; brácteas basales 2.5$3.5 \mathrm{~mm}$ de largo y ancho, pardas, prontamente caedizas, glabras; pedúnculo ausente o hasta de $2 \mathrm{~mm}$ de largo, pardo, glabro.

\section{Resumen taxonómico}

Material examinado. Mpio. Atoyac de Álvarez: $2 \mathrm{~km}$ al $\mathrm{S}$ de Nueva Dehlí por la brecha que va de Puerto del Gallo a El Paraíso (17²7'40”N, 100³1'22”O), C.A. Durán 112 (ENCB, FCME, IEB, MEXU); El Ranchito, $11 \mathrm{~km}$ al NE de El Paraíso (17²0’41”N, 100¹3'43”O), J.C. Soto 12796 (MEXU).

\section{Comentarios taxonómicos}

Esta especie se distribuye en el bosque mesófilo de montaña, entre 790 y 1100 m snm. Hasta el momento sólo se ha observado reproductiva durante el mes de mayo. Ficus lapathifolia es una especie endémica de México (Serrato et al., 2004) y se le encuentra también en Chiapas, Oaxaca, Tabasco y Veracruz. Un dibujo de la especie puede consultarse en Ibarra-Manríquez y Wendt (1992).

7. Ficus maxima Mill. Gard. Dict. (ed.8.), 1768. F. glaucescens (Liebm.) Miq. Ann. Mus. Bot. Lugduno- 
Batavum 3: 300, 1867. F. mexicana (Miq.) Miq. Ann. Mus. Bot. Lugduno-Batavum 3: 299, 1867. F. radula Humb. \& Bonpl. ex Willd. Sp. Pl. (ed. 4) 4(2): 1144, 1806. (Fig. 1D).

Árboles perennifolios de 7-18 m de alto, tallos monopódicos, sin contrafuertes definidos, fuste recto, corteza pardo grisácea, con exudado pardo pálido, escaso en la corteza, pero abundante en la madera y en ramas jóvenes, copa abierta a ligeramente densa, redondeada, verde opaca. Yema foliar terminal de 10-19 $\mathrm{mm}$ de largo, 3-5 mm de ancho; verde en material fresco, verde grisácea a ligeramente parda en material seco, pubescente; entrenudos de 1-4.5 (6.2) $\mathrm{mm}$ de largo, 4-5.5 mm de ancho, pardo rojizos, estriados, glabrescentes. Pecíolo de (9.5) 1218 (25) mm de largo, 2-2.7 mm de ancho, pardo, acanalado por el haz, con la superficie exfoliante en escamas, rugoso, ligeramente pubescente; lámina foliar de (6.5) 10.1-11.7 (13.8) cm de largo, (2.2) 4.2-6.2 (7.8) cm de ancho, 1.8-2.9 veces más larga que ancha, elíptica a elíptica lanceolada, verde amarilla a verde grisácea, crustácea; base cuneada; ápice acuminado a redondeado; haz verde oscuro a verde grisáceo, glabro a ligeramente pubescente; envés verde a verde opaco, glabro, a ligeramente pubescente, con tricomas abundantes a lo largo de la vena central, que es muy prominente y con las venas secundarias más o menos tenues, éstas últimas en 9 a 11 pares, alternas, verde amarillas a amarillas. Siconos de (1.4) 1.9-2.6 cm de largo, (0.9) 1.8-2.3 cm de diámetro, esferoides, verde opacos en material fresco, pardo verdes en material seco, ligeramente pilosos o escabrosos; ostíolo de 0.8-1.7 mm de diámetro, aplanado; brácteas basales de 1-1.5 mm de largo, 2-3.5 mm de ancho, pardas, ápice acuminado, fácilmente deciduas, densamente pubescentes; pedúnculo de 11-22 mm de largo, pardo grisáceo, pubescente.

\section{Resumen taxonómico}

Material examinado. Mpio. Arcelia: cañadaEl Naranjo, 3.2 $\mathrm{km}$ al S del campamento de Campo Morado (18 $12^{\prime} 27^{\prime} \mathrm{N}$, $\left.100^{\circ} 07^{\prime} 45^{\prime \prime O}\right)$, O. Alcántara 5813 (FCME); cañada Limón, $5.3 \mathrm{~km}$ al SO del campamento minero de Campo Morado (18 12 '27'N, 10007'45'O), R. Cruz 6082 (FCME); al E de Achotla $\left(18^{\circ} 08^{\prime} 25^{\prime \prime}\right.$ N, $100^{\circ} 09^{\prime} 50^{\prime}$ O), V.W. Steinmann 4879 (MEXU). Mpio. Atlixtac: Petatlán (17³4’27’N, 9859'15"O), C. Granados s. n. (FCME). Mpio. José Azueta: SO del caserío La Vainilla, por la cañada (1742'00”N, 101³1'30”O), C. Gallardo 282 (ENCB, FCME, MEXU), 546 (ENCB, MEXU); aproximadamente $300 \mathrm{~m}$ al $\mathrm{N}$ de caserío La Vainilla, rumbo al Calabazalito (17 $\left.42^{\circ} 00^{\prime \prime N}, 101^{\circ} 31^{\prime} 30^{\prime} \mathrm{O}\right)$, C. Gallardo 106 (ENCB, FCME, MEXU). Mpio. Tecpan de Galeana: $9 \mathrm{~km}$ al $\mathrm{N}$ de la Unión carretera a Coahuayutla $\left(18^{\circ} 18^{\prime} 57^{\prime \prime} \mathrm{N}\right.$,
10144'02"O), J.C. Soto 5994 (ENCB, MEXU, MO). Mpio. Tlacoachistlahuaca: $3 \mathrm{~km}$ de Tlacoachistlahuaca, rumbo a Ometepec $\left(16^{\circ} 48^{\prime} 06^{\prime \prime} \mathrm{N}, 98^{\circ} 18^{\prime} 24^{\prime \prime} \mathrm{O}\right)$, S. Torres 695 (FCME).

\section{Comentarios taxonómicos}

Ficus maxima se presenta en bosque tropical caducifolio, vegetación de galería y vegetación secundaria proveniente de estos tipos de vegetación, entre 240 y 1800 $\mathrm{m}$ snm. La producción de higos se ha registrado de marzo a noviembre, aunque hay datos de que se reproduce durante todo el año (Ibarra-Manríquez y Wendt, 1992). Esta especie se distribuye en ambas vertientes de México (por el Pacífico desde Sonora hasta Oaxaca y por el Atlántico en Veracruz, Tabasco y la península de Yucatán), así como en el Estado de México, Morelos, San Luis Potosí y Puebla; fuera de México se localiza desde Guatemala hasta Sudamérica y Las Antillas. Hay ilustraciones de $F$. maxima publicadas por Ibarra-Manríquez y Wendt (1992), así como en el estudio de Berg y Villavicencio (2004).

8. Ficus membranacea C. Wright. Anales Acad. Ci. Med. Habana 7: 514, 1870. (Fig. 1E).

Nombres comunes. Amate de fruto rojo, amate blanco, amate amarillo.

Árboles estranguladores o rupícolas, caducifolios o perennifolios, de 5-18 m de alto, con tallos monopódicos, sin contrafuertes, con oquedades y raíces aéreas, corteza lisa, grisácea, con exudado color crema, escaso y una copa redondeada, abierta, verde pálida. Yema foliar terminal de 9-17 mm de largo, 4-5.6 $\mathrm{mm}$ de ancho, verde, pardo grisácea, glabra; entrenudos de 5-8 (18) mm de largo por 5.7-6.2 (9) $\mathrm{mm}$ de ancho, verde pardos, verde amarillos o grisáceos, estriados, glabros. Pecíolo de 35.5-51 (73.5) $\mathrm{mm}$ de largo, 1.2-1.8 (2.7) $\mathrm{mm}$ de ancho, pardo, estriado, glabro; lámina foliar de (4.2) 7.2-18.3 (22) $\mathrm{cm}$ de largo, (3) 4.5-13.5 cm de ancho, 1.5 veces más larga que ancha, elíptica, redondeada u obovada, verde parda, verde amarilla o parda, coriácea; base truncada; ápice redondeado o mucronado, haz y envés verdes, glabros, venas secundarias amarillas o pardo verdes, 6 a 10 pares, el primero opuesto y los demás alternos. Siconos sésiles, de (7.3) 8.5-10.3 mm de largo, 7-12.5 mm de diámetro, esféricos, verdes con manchas amarillas o rojos al madurar en fresco, pardos y con manchas oscuras en material seco, ligeramente pubescentes; ostíolo de 1.1-2 mm de diámetro; brácteas basales de 4.8-6.9 mm de largo, 5-5.2 $\mathrm{mm}$ de ancho, escamosas o lisas, pubescentes en ambas superficies. 


\section{Resumen taxonómico}

Material examinado. Mpio. Atoyac de Álvarez: al NE de El Quemado (17'11'36'N, 100¹7'17'O), A. Franco s. n. (FCME). Mpio. Chilpancingo de los Bravo: 12 $\mathrm{km}$ al NO de Coyatepec, por el camino a La Esperanza (17²3'18”N, 99'36'27’O), R.M. Fonseca 1525 (ENCB, FCME, MEXU); Agua de Obispo (17¹8'50”N, 99²8'00"O), C. Gutiérrez s. n. (FCME); idem, R.M. Jiménez 4 (FCME); idem, H. Kruse 1286 (FCME, MEXU); idem, C. Sasangari 5 (FCME); rio Azinyehualco, al N de Zoyaltepec (17²0'45'N, 99³3'38'O), L.C. Rodríguez 229 (IEB, MEXU); planta hidroeléctrica Acahuizotla (17²2'59'N, 99²7'05”O), R. de Santiago 620; Rincón de la Vía $\left(17^{\circ} 17^{\prime} 15^{\prime \prime} \mathrm{N}, 99^{\circ} 28^{\prime} 55^{\prime \prime} \mathrm{O}\right), H$. Kruse 1280 (FCME, IEB, MEXU, MO), 1287 (FCME, IEB, MEXU), 1287 b (FCME, MEXU); Rincón Viejo (17¹7'40’'N, 99³0'00”O), H. Kruse 1065 (FCME, IEB, MEXU, MO). Mpio. Mochitlán: cima del cerro El Fresno (17¹5’20”N, 99²9’00”O), H. Kruse 2299 (FCME, MEXU, MO).

\section{Comentarios taxonómicos}

Especie que habita el bosque de galería colindante con el bosque tropical caducifolio y bosque tropical subcaducifolio, entre 800 y 1,150 m s.n.m. La floración y fructificación de F. membranacea se ha registrado de febrero a noviembre. El sicono de esta especie es comestible. Se distribuye en México (Jalisco, Michoacán y Morelos), Centroamérica, Sudamérica (Colombia, Ecuador, Perú) y Las Antillas.

9. Ficus obtusifolia Kunth. Nov. Gen. Sp. (quarto ed.) 2: 49, 1817. F. involuta (Liebm.) Miq. Ann. Mus. Bot. Lugduno-Batavum 3: 298, 1867. (Fig. 1F, 5).

Nombre común. Amate (Standley, 1922); higuera prieta. Árboles hemiepífitos, perennifolios, de 4-12 m de altura, tallos monopódicos, sin contrafuertes definidos, troncos huecos y raíces aéreas, corteza pardo grisácea, con exudado blanco, abundante en las ramas jóvenes, copa abierta, de formas variadas, verde oscura. Yema foliar terminal de 12.5-19 mm de largo, 3-10 mm de ancho, parda o verde negra, glabra; entrenudos de $1.5-20 \mathrm{~mm}$ de largo, 8-13.5 mm de ancho, pardos, estriados, glabros. Pecíolo de 10-32 mm de largo, 2.2-4.5 $\mathrm{mm}$ de ancho, pardo o verde amarillo, estriado, en ocasiones con un canal por el haz, glabro; lámina foliar de (6.1) $9.5-28.3 \mathrm{~cm}$ de largo, (2.7) 3.2-10.7 cm de ancho, 2.3-3 veces más larga que ancha, obovada, verde grisácea o verde pardo, coriácea, en algunas ocasiones cartácea; base cuneada o atenuada; ápice redondeado, en ocasiones ligeramente acuminado; haz pardo a verde grisáceo, glabro; envés verde amarillo, verde pardo o pardo, glabro, venas secundarias amarillas o pardas, 8 a 12 pares, ocasionalmente el primer par es opuesto, ya que generalmente todos son alternos. Siconos de 11-19 mm de largo, 11-21 mm de diámetro, esferoides o elipsoides, grisáceos, pardo o verde negruzcos, con máculas oscuras, a veces pustulados, glabros o ligeramente pubescentes; ostíolo cónico, de 2.8-5 mm de diámetro; brácteas basales de 5-12 $\mathrm{mm}$ de largo, 8-10 $\mathrm{mm}$ de ancho, pardas, ápice redondeado o ligeramente agudo, pubescentes; pedúnculo ausente o de hasta $4.5 \mathrm{~mm}$ de largo, verde o pardo, glabro.

\section{Resumen taxonómico}

Material examinado. Mpio. Acapulco de Juárez: $2 \mathrm{~km}$ al O de Puerto Marqués (1653'53”N, 9952'13”O), W. López 1228 (MEXU, XAL); $2.5 \mathrm{~km}$ al O de Puerto Marqués (1653'53'N, 9952’23”O), W. López 487, 563 (MEXU); isla La Roqueta (16 53'53”N, 9952'13”O), J. Mancilla s. n. (FCME); La Quebrada (16 $46^{\circ} 5^{\prime}$ 'N, 9940’2”O), J.C. Soto 6824 (MEXU, MO). Mpio. Arcelia: $3.5 \mathrm{~km}$ al SO del campamento minero de Campo Morado (18¹2'26.66”'N, 10007'45.03'O), R. Cruz 6151 (FCME); cañada El Naranjo, $3.2 \mathrm{~km}$ al S del campamento de Campo Morado (18 $\left.{ }^{\circ} 12^{\prime} 26.66^{\prime} \mathrm{N}, 100^{\circ} 07^{\prime} 45.03 ” O\right)$, O. Alcántara 5808 (FCME). Mpio. Atoyac de Álvarez: camino de Nueva Deli al Ranchito (17²4'16”N, 100¹1'28”O), G. Ibarra 5934 et al. (IEB, MEXU); al NE de El Quemado (17'11'36”N, 100¹7'17’'O), A. Franco s. n. (MEXU); El Ranchito, $13 \mathrm{~km} \mathrm{NE}$ de El Paraíso (17²'31'N, 100²6'3”O), J. Calónico 7894 (MEXU); Plan del Molino (17²3'59'N, 100¹9'00'O), L. Lozada 1476 (FCME, IEB). Mpio. Chilpancingo de los Bravo: $1 \mathrm{~km}$ al NO de Mazatlán, en las faldas del cerro Alquitrán (17²6’21'N, 99 28'35'O), G. Ibarra 5954 et al. (IEB, MEXU); 1 km al O de Acahuizotla, sobre el río (17 $\left.{ }^{\circ} 22^{\prime} 54^{\prime \prime} \mathrm{N}, 99^{\circ} 26^{\prime} 50^{\prime} \mathrm{O}\right)$, E. Velázquez 1247 (FCME, IEB, MEXU); $3 \mathrm{~km}$ al N de El Ocotito, sobre la carretera federal a Acapulco de Juárez (17²1'38’N, 99²8'17'O), C.A. Durán 128 (FCME, MEXU); Agua de Obispo, a orilla de la carretera, $\mathrm{km}$ 305, arriba de Barranca del Cuarenta $\left(17^{\circ} 18^{\prime} 50^{\prime \prime} \mathrm{N}\right.$, 99²8'00"O), H. Kruse 1018 (FCME, IEB, MEXU, MO), $1018 b$ (FCME, IEB); cañada a $1 \mathrm{~km}$ al SO de Agua de Obispo (17 $\left.{ }^{\circ} 18^{\prime} 48^{\prime \prime} \mathrm{N}, 99^{\circ} 28^{\prime} 52^{\prime \prime O}\right)$, L.C. Rodríguez 91 (MEXU); Chilpancigo (17³3'05'N, 99³0'03”O), J. Chavelas s. n. (FCME); Rincón de la Vía, km 31.4 de la Carretera México-Acapulco, $40 \mathrm{~km}$ al S de Chilpancingo (17¹7’15”N, 99²8'55”O), H. Kruse 441 (FCME, MEXU), s. n. (MEXU); Rincón Viejo (17¹7'40”N, 99³0'00”O), H. Kruse s. n. (FCME, IEB, MEXU). Mpio. José Azueta: cerro el Rialito, base oeste entre punta Ixtapa y el Rialito (1740’00”N, 101³9'00”O), G. Castillo 6630 (XAL); 
isla Ixtapa $\left(17^{\circ} 39^{\prime} 28^{\prime}\right.$ N, $101^{\circ} 35^{\prime} 37^{\prime}$ O), M. Pérez s. n. (MEXU); San Antonio, $9 \mathrm{~km}$ al NE de Vallecito Zaragoza (1755'49”N, 101 19'14”O), J.C. Soto 12459 (MEXU); San Antonio, a $13 \mathrm{~km}$ al NE de Vallecito de Zaragoza (1755'33”N, 101¹9’25”O), J.C. Soto 12051 (MEXU). Mpio. La Unión de Isidoro Montes De Oca: Las Pilas de Rocha, $2 \mathrm{~km}$ rio abajo de La Unión (1758'54”N, 10148'12”O), E. Guízar 3056 (IEB). Mpio. Juan R. Escudero: $40 \mathrm{~km}$ al $\mathrm{S}$ de Chilpancingo (16 $46^{\circ} 05^{\prime \prime} \mathrm{N}$, 9940’02”O), H. Kruse s. $n$. (MEXU). Mpio. Tecpan de Galeana: Cordón Grande (17³5’35'N, 10041'25’O), $H$. Adame 587 (IEB). Mpio. Teloloapan: Las Ceibitas, km 96 carretera Iguala-Arcelia,casi $20 \mathrm{~km}$ al O de Teloloapan (18²3'00”N, 10005'00”'O), H.H. Iltis 28704 (ENCB, F, MEXU). Mpio. Xochistlahuaca: $6 \mathrm{~km}$ de Xochistlahuca, dirección a Ometepec (1647'29”'N, 98¹4’44”O), G. Gaxiola 499 (FCME, IEB). Mpio. Zirándaro: $5 \mathrm{~km}$ al SE de Guayameo (18 $18^{\prime} 0^{\prime}$ N, $101^{\circ} 15^{\prime} 42^{\prime}$ O), J.C. Soto 4944 (IEB, MEXU); $9 \mathrm{~km}$ después de Guayameo, por la terracería que va a Placeres del Oro $\left(18^{\circ} 17^{\prime} 33^{\prime \prime N}\right.$, 101'13'32”O), S. Peralta 587 (FCME, IEB, MEXU); Los Parajes, $0.5 \mathrm{~km}$ al N (18 $\left.15^{\prime} 31^{\prime \prime N}, 101^{\circ} 11^{\prime} 14^{\prime \prime} \mathrm{O}\right)$, J. Calónico 14853 (FCME, HUMO, MEXU). Mpio. No determinado: brecha a playa del Sol, a $5 \mathrm{~km}$ de la Huacana, E.M. Martínez 468 (MEXU).

\section{Comentarios taxonómicos}

Especie presente en bosque tropical caducifolio, bosque tropical subcaducifolio, bosque de galería, bosque mesófilo de montaña o vegetación secundaria derivada de las coberturas de vegetación previamente mencionadas, entre (150) 810 a $1550 \mathrm{~m}$ snm Los árboles florecen y fructifican prácticamente durante todo el año (febrero a noviembre). En México se encuentra en la vertiente del Pacífico desde Sinaloa hasta Chiapas y en la vertiente del Golfo, desde Tamaulipas hasta Tabasco, así como en la península de Yucatán y centro del país (Estado de México, Puebla, San Luis Potosí y Querétaro); fuera del país se le encuentra en Centroamérica y en Sudamérica hasta Brasil y Perú. Ficus obtusifolia forma parte del complejo taxonómico del mismo nombre y que incluye entre otros miembros a F. nymphaeifolia Mill. (Berg, 1989).

10. Ficus pertusa L. f. Suppl. Pl. 442, 1781 [1782]. F. padifolia Kunth. Nov. Gen. Sp. (quarto ed.) 2: 47. 1817. (Fig. 1E).

Nombres comúnes. Amezquite; camuchito o samatito (Standley, 1922, pero este último probablemente sea amatito).

Árboles hemiepífitos o rupícolas, perennifolios, de (1) 3.7 7 (10) $\mathrm{m}$ de alto, tallos monopódicos o en pocas ocasiones simpódicos, cortos y huecos con raíces aéreas, corteza lisa, pardo grisácea o verde grisácea, con exudado blanco, escaso en la corteza pero abundante en las ramas juveniles, copa abierta y densa, verde pálida a oscura. Yema foliar terminal de 5.5-15 $\mathrm{mm}$ de largo, 3-5 $\mathrm{mm}$ de ancho, parda a parda verdosa, glabra a ligeramente pubescente; entrenudos de 4.5-8 (19.5) mm de largo, 2.3-4.2 (6) $\mathrm{mm}$ de ancho, pardo amarillos, glabros. Pecíolo de 10.2-30 (41) $\mathrm{mm}$ de largo, 0.8-1.3 mm de ancho, pardo, con un canal por el haz, glabro a ligeramente pubescente; lámina foliar de (3.1) 4.3-8.5 (12.5) cm de largo, 1-3.5 cm de ancho, 2.6-3.4 veces más larga que ancha, elíptica, elíptico ovada a lanceolada, coriácea a papirácea; base obtusa a obtuso aguda; ápice acuminado; haz verde amarillo a verde opaco, glabro; envés verde pardo o verde amarillo, glabro, venas secundarias amarillas, 8 a 10 pares, el primer par basal opuesto, los demás alternos. Siconos de (7.2) 8.513 (15.5) mm de largo, 8-13 mm de diámetro, globosos a esferoides, verdes, con máculas amarillas o rojas, las cuales son pardas al madurar, glabros; ostíolo de 2-3 mm de diámetro, hundido en una estructura anular; brácteas basales de 1.3-2.1 mm de largo, 2.1-3 mm de ancho, pardas o pardo amarillas, ápice redondeado, glabras; pedúnculo de 3-7.5 (9) mm de largo, pardo, glabro.

\section{Resumen taxonómico}

Material examinado. Mpio. Acapulco de Juárez: 2.5 km al O de Puerto Marqués (1653'53'N, 9952'23'O), W. López 700 (ENCB, MEXU, XAL); Acapulco (1651'47'N, 98 53'47”O), E.A. Palmer 62 (F); cerro de Cacahuatepec, laguna de Tres Palos (1641'38'N, 99³8'13'O), $N$. Diego 5030 (ENCB, IEB); hotel Copacabana Acapulco (1646'25'N, 99³6'04”O), L. Boege 449 (MEXU); La Estación, orilla de la laguna de Tres Palos (16 41'37'N, 99³8'12”O), N. Diego 4415 (FCME), Parque Nacional El Veladero, cerro Caraval (16 $\left.55^{\prime} 54^{\prime \prime} \mathrm{N}, 99^{\circ} 53^{\prime} 12^{\prime} \mathrm{O}\right)$, N. Noriega 335 (FCME). Mpio. Atoyac de Álvarez: cerro Prieto (17 $\left.12^{\circ} 31^{\prime \prime N}, 100^{\circ} 26^{\prime} 03^{\prime \prime O}\right)$, G. Espinosa 6 (FCME, MEXU); Rincón de La Parota, sobre el puente que cruza el río Parota $\left(17^{\circ} 14^{\prime} 00^{\prime \prime} \mathrm{N}, 100^{\circ} 23^{\prime} 00^{\prime} \mathrm{O}\right)$, C.A. Durán 117 (ENCB, FCME, IEB, MEXU). Mpio. Bénito Juárez: Llano Real, laguna de Mitla (1704'41'N, 100²6'03"O), L. Lozada 889 (ENCB, FCME, IEB). Mpio. Buenavista de Cuéllar: $6 \mathrm{~km}$ al $\mathrm{N}$ de Buenavista de Cuellar, carretera federal Cuernavaca-Iguala (18 37' $52^{\prime}$ 'N, 99²4'09”O), C.A. Durán 95 (FCME, IEB, MEXU). Mpio. Chilpancingo de los Bravo: $2.5 \mathrm{~km}$ al SO de Soyaltepec por el camino al cerro El Toro (17¹9'10’'N, 99³3'14’'O), L.C. Rodríguez 233 (IEB, MEXU); Mazatlán, falda E del cerro El Alquitrán (17²7'1”N, 99²7'54”O), $H$. Kruse 2347 (FCME, IEB, MEXU, MO); camino a El 
Alquitrán (17²6’40”N, 99²9'04”O), L. Lozada 2718 (ENCB, FCME, IEB, MEXU); estación de microondas El Alquitrán (17²6’40”N, 99²9’04”O), L. Lozada 2347 (ENCB, FCME, IEB). Mpio. Coyuca de Benítez: El Carrizal, canal, $1 \mathrm{~km}$ NO, laguna de Mitla (16 $57^{\circ} 45^{\prime \prime} \mathrm{N}$, $\left.100^{\circ} 08^{\prime} 21^{\prime \prime} \mathrm{O}\right)$, L. Lozada 675 (ENCB, FCME); isla de Los Tamarindos, Laguna de Mitla (1700'42”N , 10001'06”O), L. Lozada 854 (ENCB, FCME, IEB); arroyo El Zapote, laguna de Mitla (1708'54'N, 10040'33”O), L. Lozada 542 (FCME, IEB); laguna de Mitla, $0.5 \mathrm{~km}$ al SE de El Zapote (1700'20'N, 100¹3'07'O), G. Díaz 35 (FCME, IEB). Mpio. Coyuca de Catalán: San Antonio, Distrito Montes de Oca, G.B. Hinton 11509 (ENCB, F, HUMO, MEXU, MO). Mpio. General Heliodoro Castillo: Tlacotepec, $3.5 \mathrm{~km}$ al O camino a Huautla $\left(17^{\circ} 47^{\prime} 36^{\prime \prime} \mathrm{N}\right.$, 10000'36"O), R. Cruz 3977 (FCME, IEB, MEXU). Mpio. Iguala de la Independencia: Iguala (18 $20^{\prime} 40^{\prime \prime} \mathrm{N}$, 99³2'20'O), J. Freeland 59 (MEXU). Mpio. José Azueta: $9 \mathrm{~km}$ al $\mathrm{N}$ de Vallecitos de Zaragoza, sobre la carretera Zihuatanejo-Ciudad Altamirano (17 ${ }^{\circ} 55^{\prime} 18^{\prime}$ 'N, 101¹9'12”O), J.C. Soto 5034 (IEB, MEXU); alrededores del caserío “La Vainilla" (1741'43”N, 101³1'23”O), C. Gallardo 80 (FCME, MEXU); El Limoncito, a $4 \mathrm{~km}$ al $\mathrm{N}$ de Real de Guadalupe (1801'24'N, 101¹8'42'O), F. González 6551 (IEB, MEXU); San Antonio, $11 \mathrm{~km}$ al N de Vallecitos de Zaragoza, sobre la carretera ZihuatanejoCiudad Altamirano (1755'18'N, 101¹9'12'O), J.C. Soto 5053 (IEB, MEXU). Mpio. Juan R. Escudero: NO de El Tepeguaje, por la vereda a Omitlán $\left(17^{\circ} 09^{\prime} 56^{\prime} \mathrm{N}\right.$, 99³1'35”O), R.M. Fonseca 3141 (FCME, IEB); Tierra Colorada, en la falda de un cerro entre 2 grandes rocas de granito, cerca de la orilla del río Omitlan $\left(17^{\circ} 9^{\prime} 56^{\prime} \mathrm{N}\right.$, 99³1'35'O), H. Kruse 1070 (ENCB, FCME, IEB, MEXU). Mpio. La Unión de Isidoro Montes de Oca: El Cedral, a 19 km de la desviación a La Unión (1757'42’'N, 101³9'23”O), J.C. Soto 9586 (MEXU). Mpio. Ometepec: $1 \mathrm{~km}$ de Piedra Boluda, dirección Las Iguanas (16³9'02”N, 98²6’59”O), G. Gaxiola 434 (FCME, IEB, MEXU); Ometepec (1641'08'N, 98²4'20'O), L. García s. n. (FCME). Mpio. Petatlán: La Florida, $31 \mathrm{~km}$ al EN de Coyuquilla $\left(17^{\circ} 32^{\prime} 10^{\prime \prime} \mathrm{N}, 101^{\circ} 16^{\prime} 10^{\prime} \mathrm{O}\right)$, J.C. Soto 12311 (MEXU, MO); microondas Las Rocas, lado S de la laguna de San Valentín (17²7'31'N, 101¹5'57’O), N. Diego 6549 (MEXU). Mpio. San Luis Acatlán: 6 $\mathrm{km}$ al SO de Jolotichan (1648'26”N, 9844'13'O), J. Mejía s. n. (FCME). Mpio. Taxco de Alarcón: Atzala, $6.6 \mathrm{~km}$ al SE de Chichila (18³0'21'”N, 99³9'23”O), J. Calónico 8936 (IEB). Mpio. Tixtla de Guerrero: cerro La Virgen de Guadalupe (17²7’00'N, 10009'00'O), B. Ludlow 138 (IEB, MEXU); El Puente de El Ranchito, 5 $\mathrm{km}$ antes de Tixtla, sobre el río de la presa (17³4'29'N, 99²3'50”O), M. Huerta 45 (ENCB, FCME, IEB,
MEXU); ladera N del cerro Jazmín, $5 \mathrm{~km}$ al SO de Tixtla (17³3'11'N, 99²6'06”O), A. Rodríguez 39 (IEB). Mpio. Tlacoachistlahuaca: $4.5 \mathrm{~km}$ al $\mathrm{S}$ de San Isidro (1653'22”'N, 98¹8'00”O), L. Lozada 1542 (ENCB, FCME, IEB). Mpio. no determinado: Manchón, District Mina, G.B. Hinton 9618 (F, HUMO), 10083 (ENCB, HUMO, MO).

\section{Comentarios taxonómicos}

Especie que habita en el bosque tropical caducifolio, bosque de galería, bosque de Quercus y vegetación secundaria donde se encontraban estos tipos de vegetación, desde el nivel del mar hasta $1550 \mathrm{~m}$ de altitud. La floración y fructificación se han registrado todo el año. Ficus pertusa presenta una amplia distribución en México, se encuentra desde Sonora hasta Chiapas y desde Tamaulipas hasta Campeche y la península de Yucatán, así como en varios estados del centro del país (Aguascalientes, Chihuahua, Durango, Estado de México, Guanajuato, Hidalgo, Morelos, Puebla y San Luis Potosí); fuera de México se registra de Centroamérica, Sudamérica (hasta Brasil) y Las Antillas. Ficus pertusa forma parte del complejo taxonómico del mismo nombre, que incluye, entre otras especies, a F. pallida, F. schumacheri y F. trachelosyce (Berg, 1989, 2007).

11. Ficus petiolaris Kunth. Nov. Gen. Sp. (quarto ed.) 2: 49, 1817.

Nombres comunes. Amacoztic, amate corazón, texcaloma. De acuerdo con Standley (1922) se le conoce también como amate amarillo, tepeamatl y tepeamte (probablemente el nombre correcto sea tepeamate). (Fig. 1A, 6).

Árboles rupícolas, caducifolios, de 7-22 m de altura, tallos monopódicos o simpódicos, fuste regularmente delgado, contrafuertes raramente presentes, alcanzando excepcionalmente un diámetro de hasta $2 \mathrm{~m}$, corteza amarilla, amarillo grisácea o amarillo verdosa, con exudado blanco, abundante, copa amplia y redondeada, verde pálida. Yema foliar terminal de (12) 19-74 mm de largo, 4.5-11 mm de ancho, parda o pardo amarilla, glabra o densamente pubescente, con tricomas blancos; entrenudos de 2-10 mm de largo, 6-12 $\mathrm{mm}$ de ancho, pardo amarillos, estriados, exfoliantes, glabros. Pecíolo de (3.7) 5.5-10.8 (14.7) $\mathrm{mm}$ de largo, 1.7-3.8 $\mathrm{mm}$ de ancho, pardo a verde rojizo, glabro o pubescente; lámina foliar de (3.7) 4.9-14.8 cm de largo, (3.2) 5.3-15.6 cm de ancho, 0.9-1.1 veces más larga que ancho, cordiforme, verde, verde amarilla o parda, coriácea o cartácea, base cordada; ápice redondeado a apiculado; haz verde oscuro o pardo, glabro; envés pardo amarillo o verde grisáceo, con domacios en la base de la lámina, venas secundarias amarillas, 6 a 11 pares, los 
primeros 3 o 4 pares opuestos, los demás alternos. Siconos de 7-9 mm de largo, 6.5-10.5 mm de diámetro, esferoides a ligeramente piriformes, verde amarillos, rojizos o amarillos, con máculas rojas a oscuras en material fresco, pardos en material seco, glabros a densamente pubescentes; ostíolo de 1.9-3 mm de diámetro, ocasionalmente cónico; brácteas basales de $2 \mathrm{~mm}$ de largo, 3-3.2 $\mathrm{mm}$ de ancho, glabras o ligeramente pubescentes, verde oscuro, pardas, con el ápice redondeado, persistentes; pedúnculo de (6) 20-60 mm de largo, $1 \mathrm{~mm}$ de ancho, verde oscuro, glabro o ligeramente pubescente.

\section{Resumen taxonómico}

Material examinado. Mpio. Acapulco de Juárez: 2.5 $\mathrm{km}$ al O de Puerto Marqués (1653'53”N, 9952'23”O), W. López 483, 543, 713 (MEXU), 1126 (ENCB, MEXU, XAL), 1157 (MEXU, MO). Mpio. Buenavista de Cuéllar: $6 \mathrm{~km}$ al $\mathrm{N}$ de Buenavista de Cuellar, carretera federal Cuernavaca-Iguala (18³7'52'N, 99²4’01”O), C.A.Durán 94 (FCME, IEB). Mpio. Chilpancingo de los Bravo: 1 km al NO de Mazatlán, en las faldas del cerro Alquitrán (17²6’21'N, 99²8’35'O), G. Ibarra 5932 et al., 5933 et al. (IEB, MEXU); $3 \mathrm{~km}$ al O de Chilpancingo (17'33'14'”N, 99²9'59'O), M. Blanco 120 (ENCB, MEXU); 16 km NO de Chilpancingo sobre la carretera que va a Chichihualco (17³5’32”N, 99³1'11'O), C.A. Durán 127 (FCME, IEB); al O de Chilpancingo (17³3'14’N, 99³9'59’O), $J$. Chavelas 18 (ENCB, INIF, MEXU); aproximadamente a 500 m del poblado Mazatlán hacia Chilpancingo, en la curva de la carretera $\left(17^{\circ} 26^{\prime} 17^{\prime \prime} \mathrm{N}, 9^{\circ} 28^{\prime} 33^{\prime \prime} \mathrm{O}\right), \mathrm{N}$. González 44 (IEB); cerro de los Bueyes al $\mathrm{N}$ de Chilpancingo (17³5'20'N , 99³0'41'O), J. Chavelas 1785 (INIF); km 1 de la carretera Chichihualco-Chilpancingo (17³4'00”N, 99³0'31'O), H. Kruse 2725 (FCME, MEXU); Mazatlán, falda E del cerro Alquitrán (17²6’01'N, 99²7'54”O), H. Kruse 2090 (FCME, MEXU), 2727 (FCME, IEB, MEXU, MO). Mpio. Cutzamala de Pinzón: 4 km al SO de Cañas Viejas, $20 \mathrm{~km}$ al NO de Nuevo Galena (18³6’01”N, 10040’34”O), F. González 6100 (MEXU). Mpio. Eduardo Neri: puente Agustín Lorenzo, km 61 carretera Iguala-Chilpancingo, sobre el acantilado a la orilla del río $\left(17^{\circ} 50^{\prime} 13^{\prime} \mathrm{N}, 9^{\circ} 04^{\prime} 08^{\prime} \mathrm{O}\right), \quad N$. González 31 (IEB); Zumpango del Río, $5 \mathrm{~km}$ al S (17³6’30”N, 99`31'04'O), H. Kruse 2714 (FCME, IEB, MEXU). Mpio. Huitzuco de los Figueroa: $4 \mathrm{~km}$ al $\mathrm{N}$ de San Francisco Ozomatlán (1755'35'N, 99²0’21'O), A. Vargas 323 (FCME). Mpio. Iguala de la Independencia: $15 \mathrm{~km}$ al S de Iguala, sobre la carretera federal a Chilpancingo (18¹1'38’'N, 99³2’49”O), N. González 29 (IEB); cañón de la Mano, entre los Amates y El Naranjo, $10 \mathrm{~km}$ al N de Iguala, por el Ferrocarril (18²3'54’N, 99³2’06”O),
C. Catalán 214 (IEB). Mpio. Juan R. Escudero: Tierra Colorada (1709'56”N, 99³1'35”O), H. Kruse 1060 (FCME, MEXU). Mpio. La Unión de Isidoro Montes de Oca: Cundancito, $15 \mathrm{~km}$ al NE Zihuatanejo-Ciudad Altamirano (18 1'22”N, 1017'27’O), E.M. Martínez 4291 (MEXU). Mpio. Mochitlán: Mazatlán, 3 km al N del Salto Valadéz (17²7'30”N, 99²8'10”O), H. Kruse 2085, 2726 (FCME), 2709 (FCME, IEB, MO), 2716 (MO); Palo Blanco, km 298 (17²4'00”N, 99²8'00”O), H. Kruse 445 (ENCB, FCME, MEXU); Tepechicotlán, zona centro $\left(17^{\circ} 29^{\prime} 00^{\prime \prime} \mathrm{N}, 9^{\circ} 25^{\prime} 00^{\prime}\right.$ 'O), J.E. Elizondo 85 (INIF). Mpio. Taxco de Alarcón: Cacahuamilpa, 3 km al O, rumbo a Piedras Negras (1841'01'”N, 99³1'47”O), J. Calónico 8582 (FCME, HUMO); Taxco (18³3'15’N, 99³6'17'O), W.M.C. Leavenworth 949 (F). Mpio. Tixtla de Guerrero: cerro a la orilla de la laguna de Huiziltepec (1745'30’'N, 99²7’30”O), B. Ludlow 371 (FCME, IEB, MEXU); Tixtla, cerro La Virgen de Guadalupe (17²7'00'N, 10009'00'O), B. Ludlow 152 (ENCB, FCME, IEB, MEXU). Mpio. Tlapa de Comonfort: $7 \mathrm{~km}$ al O de Tlapa de Comonfort, frente a la gasolinería sobre la carretera federal $\left(17^{\circ} 32^{\prime} 49^{\prime \prime} \mathrm{N}, 98^{\circ} 36^{\prime} 4^{\prime}\right.$ 'O), C.A. Durán 64 (FCME, IEB, MEXU).

\section{Comentarios taxonómicos}

Especie que prospera en el bosque tropical caducifolio, bosque de Quercus y vegetación secundaria que proviene de aquéllos, entre 620 y 1600 m snm. La floración y fructificación se registró de marzo a noviembre. Esta especie se encuentra en las casas del área de estudio como árbol de sombra o para alimentar animales domésticos y tiene un gran potencial como planta ornamental, uso que actualmente se le da en Brasil (Carauta y Diaz, 2002); la corteza se utiliza para la elaboración de "papel amate". Esta especie es endémica de México (Serrato et al., 2004) y se distribuye en la vertiente del Pacífico, desde Sonora hasta Oaxaca, así como en Chihuahua, Durango, Estado de México, Morelos y Puebla. Ficus petiolaris está estrechamente relacionada con $F$. palmeri S. Watson, por lo que Felger y Lowe (1970) proponen la existencia de 2 subespecies (F. brandegei (Standl.) Felger et Lowe y $F$. palmeri (S. Watson) Felger et Lowe), mientras que Carvajal et al. (2001) adicionan la subsp. jaliscana (S. Watson) Carvajal y la subsp. petiolaris. Estos estudios se basaron principalmente en la presencia o ausencia de pubescencia en las ramillas de la estación, hojas y siconos, en el color de las nervaduras secundarias de las hojas y en determinar si los siconos tienen o carecen de máculas. Estas características no son consistentes con lo observado en el material botánico colectado en Guerrero, por lo que no fue posible usarlas de manera consistente para delimitarlo. 
12. Ficus pringlei S. Watson. Proc. Am. Acad. 26: 150, 1891. (Fig. 1C).

Árboles rupícolas, caducifolios, de 6-12 (20) m de altura, tallos monopódicos, oquedades y raíces aéreas, sin contrafuertes, con exudado blanco y una copa de corta a amplia y generalmente redondeada, verde opaca. Yema foliar terminal de 6-12 $\mathrm{mm}$ de largo, 4-10 $\mathrm{mm}$ de ancho, parda a pardo grisácea, pubescente; entrenudos de12.5-14 mm de largo, 2.8-5 mm de ancho, pardo rojizos, vilosos cuando son jóvenes, a veces glabrescentes, pardos a grisáceos. Pecíolo de 5-20 mm de largo, 1-1.8 mm de ancho, pardo, con un canal por el haz, pubescente; lámina foliar de (2.3) 5.2-7.5 cm de largo, (1.9) $5.8 \mathrm{~mm}$ de largo, 0.8-1.2 veces más larga que ancha, elíptica a ovada, verde amarilla o verde opaca, coriácea; base cordada; ápice redondeado o ligeramente acuminado; haz glabrescente; envés verde grisáceo, pubescente en las venas secundarias y terciarias, las primeras pardo amarillas, de 4 a 7 pares, el primer par opuesto, los demás alternos. Siconos de 5$8 \mathrm{~mm}$ de largo, 4-8 $\mathrm{mm}$ de diámetro, esferoides, pardo grisáceos, con máculas circulares y glabros o bien sin máculas circulares, pero pubescentes; ostíolo de $2.5 \mathrm{~mm}$ de diámetro, prominente, cónico; brácteas basales de 2.8$4.8 \mathrm{~mm}$ de largo por $4 \mathrm{~mm}$ de ancho, pardas, con el ápice redondeado, ligeramente pubescentes; pedúnculo de 2-3 $\mathrm{mm}$ de largo, verde o verde pardo, pubescente.

\section{Resumen taxonómico}

Material examinado. Mpio. Cutzamala de Pinzón: $8 \mathrm{~km}$ al NO de Cañas Viejas (18³6’21'N, 10040’35”O), F. González 6119, 6135 (MEXU). Mpio. José Azueta: 1.6 $\mathrm{km}$ SO del caserio La Vainilla, cerros que limitan La Mesa del Mango (1742’00”N, 101³1'30”O), C. Gallardo 720 (FCME, MEXU).

\section{Comentarios taxonómicos}

F. pringlei es una especie con distribución muy localizada en Guerrero, que habita exclusivamente en el bosque tropical caducifolio, a 410 m s.n.m. El periodo de floración y fructificación se ha registrado sólo en los meses de julio y diciembre, aunque es muy probable que ocurra durante la mayor parte del año. No se le adjudican usos en la zona de estudio. Es una especie endémica de México (Serrato et al., 2004), que se distribuye también en Colima, Jalisco, Michoacán y Nayarit.

13. Ficus velutina Humb. et Bonpl. ex Willd. Sp. Pl. (quarto ed.) (Fig. 1C, 7).

Nombre común. Amate.

Árboles hemiepífitos o estranguladores, caducifolios o perennifolios, de 10-22 m de alto, con tallos monopódicos y con numerosas raíces aéreas anastomosadas, corteza lisa pardo gris o pardo rojiza, fisurada, con exudado blanco a ligeramente amarillo, abundante, copa amplia y densa, verde oscuro. Yema foliar terminal de $10-18 \mathrm{~mm}$ de largo, 4-11 mm de ancho, pardo ferrugínea, densamente serícea; entrenudos de 1.5-2.3 (4) cm de largo, 4-7 mm de ancho, pardos, estriados, glabros o ligeramente pubescentes. Pecíolo de 15-30 mm de largo, 1.5-3 mm de ancho, verde negruzco o verde grisáceo, glabro a ligeramente piloso; lámina foliar de (8) $13-22.5 \mathrm{~cm}$ de (4.5) 5.5-8.7 (10.2) cm de ancho, 1.7-2.3 veces más larga que ancha, elíptica oblonga, pardo grisácea o amarillo verdosa, coriácea; base obtuso redondeada a ligeramente subcordada; ápice obtuso, redondeado a ligeramente agudo; haz verde grisáceo, verde pardo, glabro; envés verde opaco a verde rojizo, vena central y venas secundarias pubescentes, raramente glabras, 10 a 14 pares de venas secundarias, los 2 primeros pares opuestos, condición que a veces puede presentarse hasta el cuarto par, los demás alternos. Siconos de 1118 (24) mm de largo, 13-18 mm de diámetro, esferoides, verdes en fresco, verrucosos, con tricomas rojizos, grises o pardos, glabrescentes en material seco; ostíolo de 3.1-6 $\mathrm{mm}$ de diámetro, con una cicatriz anular evidente, flores blanquecinas; brácteas basales de 2-3 mm de largo, 3-3.8 $\mathrm{mm}$ de ancho, pardo oscuro, ápice redondeado, cubiertas por una fina pubescencia ferrugínea; pedúnculo de 2-4.5 $\mathrm{mm}$ de largo, verde a verde pardo, pubescente o raramente glabrescente.

\section{Resumen taxonómico}

Material examinado. Mpio. Acapulco de Juárez: 18 km al NE de El Paraíso, carretera a Atoyac (1653'08'N, 9947'33”O), J.C. Soto 5229 (MEXU). Mpio. Atoyac de Álvarez: 44 km al NE de Atoyac, camino a El Paraíso (17'12’32'N, 100²6'03”O), E.M. Martínez 3748 (IEB, MEXU, MO, UAMIZ); El Molote (17²5'0’'N, 100¹0'0”O), L. Lozada 2659 (FCME, MEXU); El Ranchito, $11 \mathrm{~km}$ al EN de El Paraìso (17 $20^{\circ} 41^{\prime \prime} \mathrm{N}$, 100¹3'43”O), J.C. Soto 5241, 12797 (MEXU). Mpio. Chilpancingo de los Bravo: cercanías de Tepozonalco, camino Chilpancingo-Omiltemi (17 $33^{\circ} 22^{\prime}$ N 99 $41^{\prime} 16^{\circ}$ O), F.G. Lorea 591 (FCME, MEXU); Jalapa, en el km 13.5 de la carretera a Chichihualco $\left(17^{\circ} 37^{\prime} 40^{\prime}\right.$ 'N, 99³5'40”O), H. Kruse 1662 (FCME, MEXU, MO), 2010 (FCME, IEB, MEXU); Jalapa, $15 \mathrm{~km}$ al NO de Chilpancingo (17³7'12”N, 99³7'19”O), C.A. Durán 125 (FCME); O de Chilpancingo (17²0'45'N, 99 33'38'O), A.J. Sharp 441443 (MEXU). Mpio. Leonardo Bravo: La Laguna, $18 \mathrm{~km}$ al SO de Xochipala, Chichihualco (1748'43”N, 99³8'14”O), J.C. Soto 5172 (MEXU). 


\section{Comentarios taxonómicos}

Especie que habita en el bosque tropical caducifolio, bosque de Pinus, bosque de Quercus y bosque mesófilo de montaña, desde el nivel del mar hasta $2100 \mathrm{~m}$ snm. La floración y fructificación se presentan de marzo hasta diciembre. Se usa como árbol de sombra para los cafetales en el bosque mesófilo de montaña. Se distribuye en la vertiente del Pacífico desde Sinaloa hasta Chiapas, así como en Estado de México, Morelos, Puebla y Veracruz; fuera del país se le encuentra desde Guatemala hasta Panamá.

14. Ficus yoponensis Desv. Ann. Sci. Nat. Bot. 2, 18: 310. T. 8, Fig. 1 (!) 1842. (Fig. 1F).

Árboles perennifolios de $10-35 \mathrm{~m}$ de alto, tallos monopódicos, contrafuertes definidos, fuste recto, corteza lisa, grisácea, con exudado blanco, abundante, con una copa densa y redondeada, verde pálida. Yema foliar terminal de 10-80 $\mathrm{mm}$ de largo, 2-4 $\mathrm{mm}$ de ancho, verde a verde amarilla en fresco, parda o verde en material seco, glabra o pilosa en la base; entrenudos de 5-10 mm de largo, 2-3.5 $\mathrm{mm}$ de ancho, pardos, amarillos o grises, lisos, glabros. Pecíolo de 12-30-mm de largo, 2-3 $\mathrm{mm}$ de ancho, pardo verde o verde oscuro, estriado, glabro; lámina foliar de 7$13.5 \mathrm{~cm}$ de largo, 3-6.5 cm de ancho, 2.3-3.2 veces más larga que ancha, oblanceolada a elíptica, verde amarilla o verde opaca, coriácea; base atenuada a ligeramente truncada; ápice acuminado o cortamente apiculado; haz verde, glabro o en raras ocasiones seríceo; envés verde amarillento, glabro o seríceo, venas secundarias amarillas, tenues, 14 a 19 pares, opuestos en el primer y segundo par, los demás subopuestos. Siconos de 8-18 mm de largo, 8-18 $\mathrm{mm}$ de diámetro, esferoides, verdes con máculas circulares u ovaladas, amarillas o blancas en material fresco, verdes o pardos, con máculas amarillas o pardos en material seco, glabros, flores blancas en fresco; ostíolo de 1-1.7 mm de diámetro; brácteas basales de 0.4-1.2 mm de largo, 1-1.8 mm de ancho, pardas, con el ápice agudo, glabras; pedúnculo de 6-9 $\mathrm{mm}$ de largo, 1-1.5 $\mathrm{mm}$ de ancho, verde opaco o pardo, glabro.

\section{Resumen taxonómico}

Material examinado. CHIAPAS: Mpio. Ocosingo. Zona arqueológica de Yaxchilán, (16 53'53”N, 100¹2'12”O), A. Rincón 974 (F, MEXU, MO). GUERRERO. Mpio. Atoyac de Álvarez: $4 \mathrm{~km}$ al NE de El Paraíso (17²1'49'N, 9057'52”O), G. Ibarra et al. 5940 (IEB, MEXU). OAXACA. Municipio Santa María Chimalapa: paso de la Cueva del río del Corte, cerca de 2-4 km al NE de Santa María (1656’00”N, 9440’00”O),
H. Hernández 2029 (MO).

\section{Comentarios taxonómicos}

La colecta de esta especie en el área de estudio fue realizada en vegetación ruderal con elementos remanentes de un bosque tropical perennifolio a $930 \mathrm{~m} \mathrm{snm}$. La floración y fructificación probablemente se presentan durante todo el año. La presencia de F. yoponensis en Puebla y Veracruz hasta Campeche y Chiapas, así como Oaxaca está documentada. No se había recolectado en Guerrero. Se distribuye en Centroamérica y en Sudamérica hasta Bolivia. En Ibarra-Manríquez y Wendt (1992), así como en Berg y Villavicencio (2004 ) se encuentran publicadas ilustraciones de esta especie.

\section{Discusión}

La diversidad de especies de Ficus en Veracruz, Chiapas y Oaxaca es de 20,19 y 18 especies, respectivamente (Serrato et al., 2004). Los resultados obtenidos en este trabajo ubican a Guerrero como la cuarta entidad más diversa del género en México, con 13 especies, 5 de las cuales se registran por primera vez dentro de sus límites geopolíticos (F. crocata, F. lapathifolia, F. membranacea, $F$. pringlei y $F$. yoponensis). Con respecto al registro previo de F. lapathifolia por Standley (1922), es necesario aclarar que se trató de la identificación incorrecta de una especie del subgénero Urostigma. Burger (1977) indicó que bajo este epíteto específico se determinó material perteneciente a $F$. morazaniana W.C. Burger, un nombre que actualmente se considera sinónimo de $F$. crocata (Miq.) Miq. (Berg y Villavicencio, 2004). En Standley (1922) y en listados florísticos de distintas zonas del área de estudio se mencionan 22 especies de Ficus, 11 de las cuales están consideradas actualmente como sinónimos. Para el caso de $F$. costaricana y $F$. inamoaena puede afirmarse que son taxones que no se encuentran en México y que su registro para el área de estudio es incorrecto.

De las 13 especies reconocidas para Guerrero, 8 se encontraron en la vegetación de galería y/o el bosque tropical caducifolio, lo que en parte se explica, porque este último es el tipo de vegetación más extendido en la entidad $(28.7 \%)$, aunque la estimación de este porcentaje lo comparte con el bosque tropical subcaducifolio (Palacio-Prieto et al., 2000). Lo anterior confirma su importancia en México, donde se le ha propuesto dentro de las ecorregiones prioritarias para la conservación de la biodiversidad, tanto mundial (Olson y Dinerstein, 2002) como nacional (Ceballos y García, 1995; Cué-Bär et al., 2006). La recurrente presencia de las especies de Ficus con 

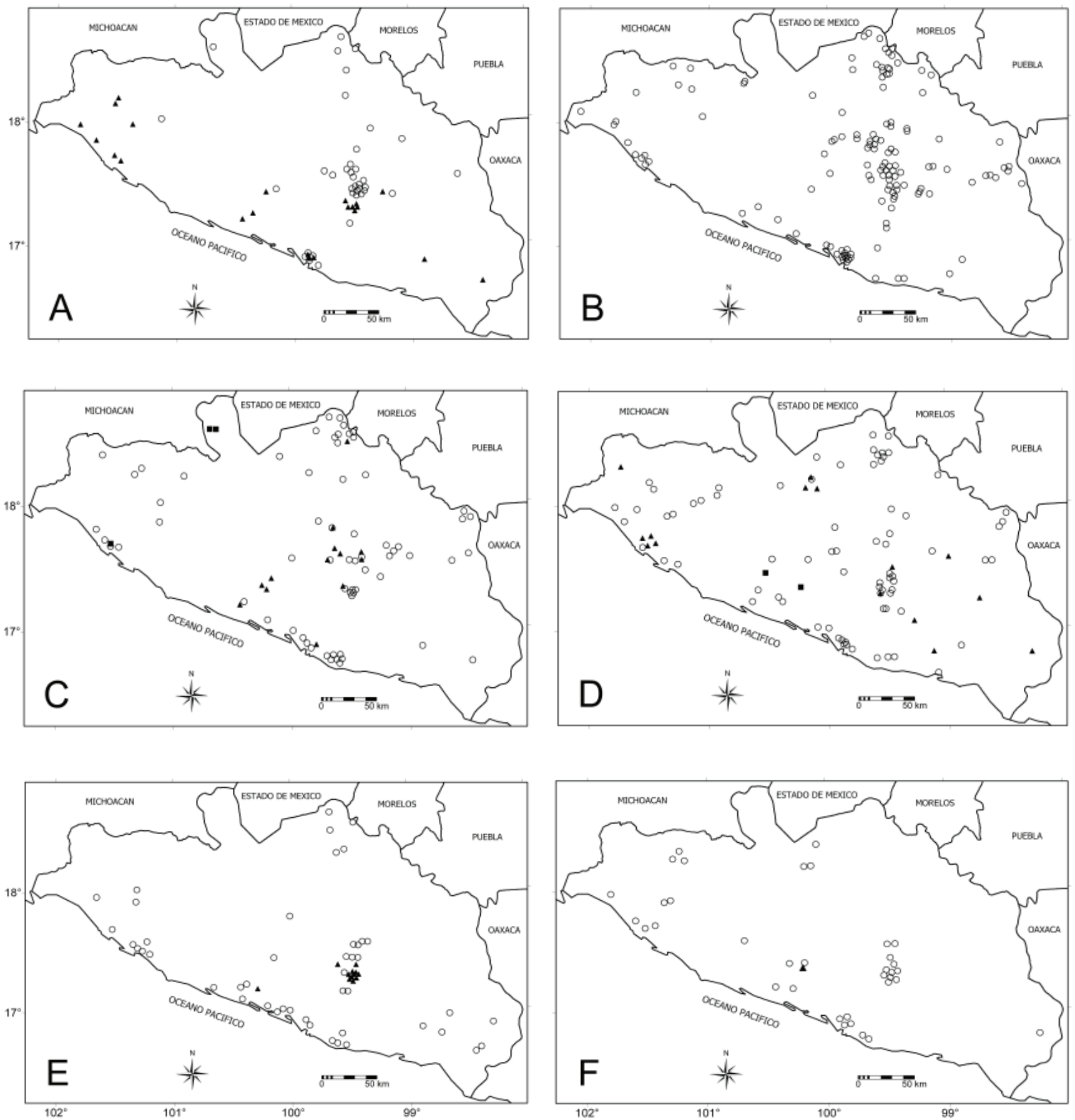

Figura 1. Mapas de la distribución geográfica de las especies de Ficus en el estado de Guerrero. A) Ficus citrifolia (triángulo), F. petiolaris (círculo); B) F. cotinifolia; C) F. crocata (círculo), F. pringlei (cuadro), F. velutina (triángulo); D) F. insipida (círculo), F. lapathifolia (cuadro), F. maxima (triángulo); E) F. membranacea (triángulo), F. pertusa (círculo), y F) F. obtusifolia (círculo), F. yoponensis (triángulo). 


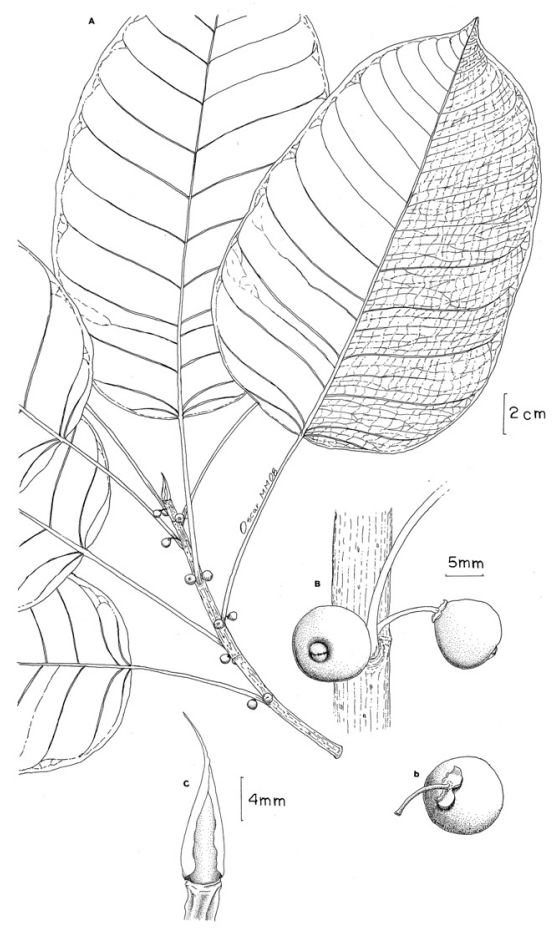

Figura 2. Ficus citrifolia (Gual 557). A rama con hojas y siconos; $\mathrm{B}$, yema foliar; $\mathrm{C}$, siconos; $\mathrm{D}$, brácteas basales del sicono.

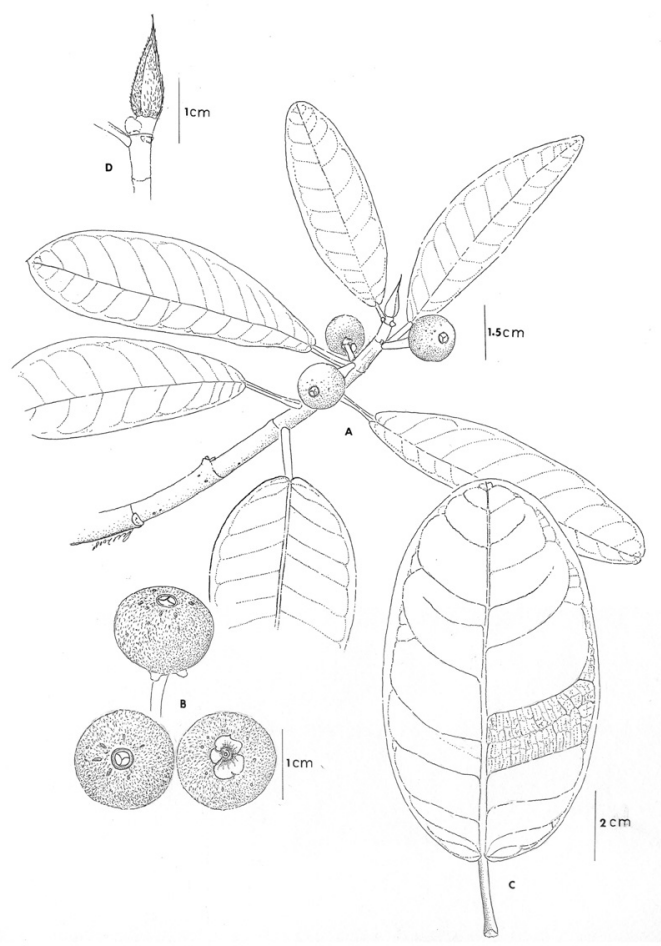

Figura 4. Ficus crocata (Diego y Ludlow, 7349). A, rama con hojas y siconos; B, yema foliar; C, venación de la lámina foliar; $\mathrm{D}$, brácteas basales y ostíolo de los siconos.

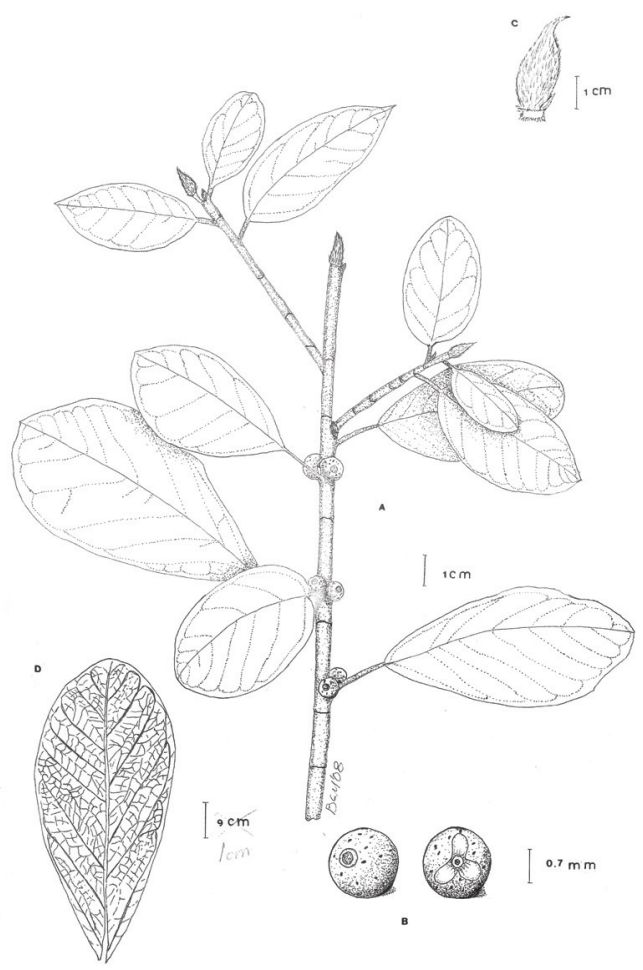

Figura 3. Ficus cotinifolia (Durán et al. 124). A, rama con hojas y siconos; B, yema foliar; C, venación de la lámina foliar; D, siconos.

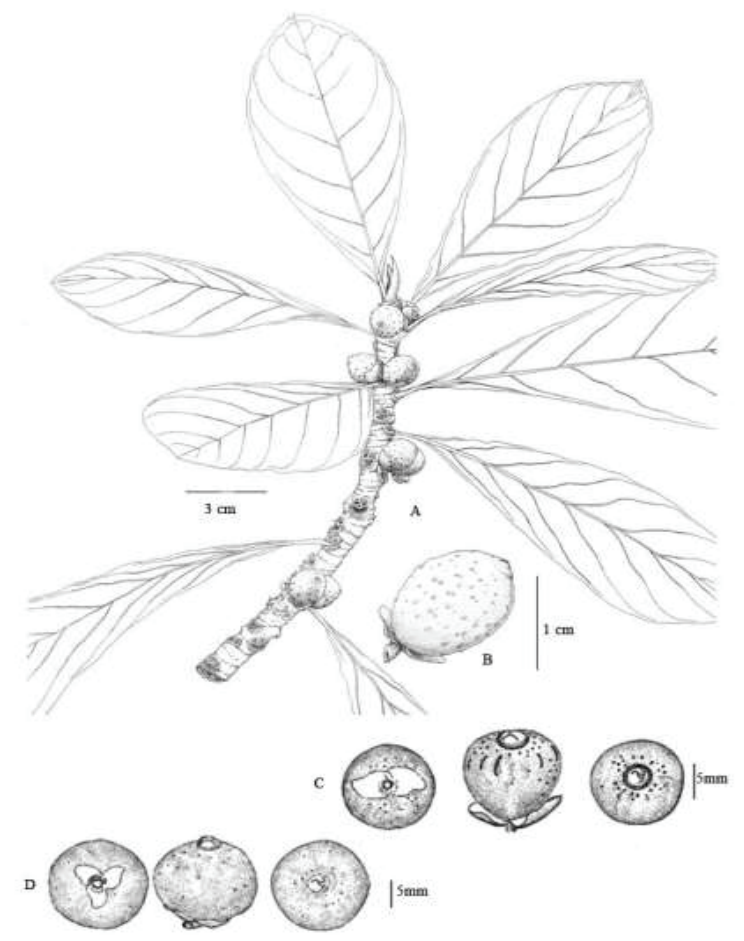

Figura 5. Ficus obtusifolia (Velázquez, 1247). A, rama con hojas y siconos; $\mathrm{B}$, sicono; $\mathrm{C}$ y D, detalles de las brácteas basales y el ostíolo de los siconos 


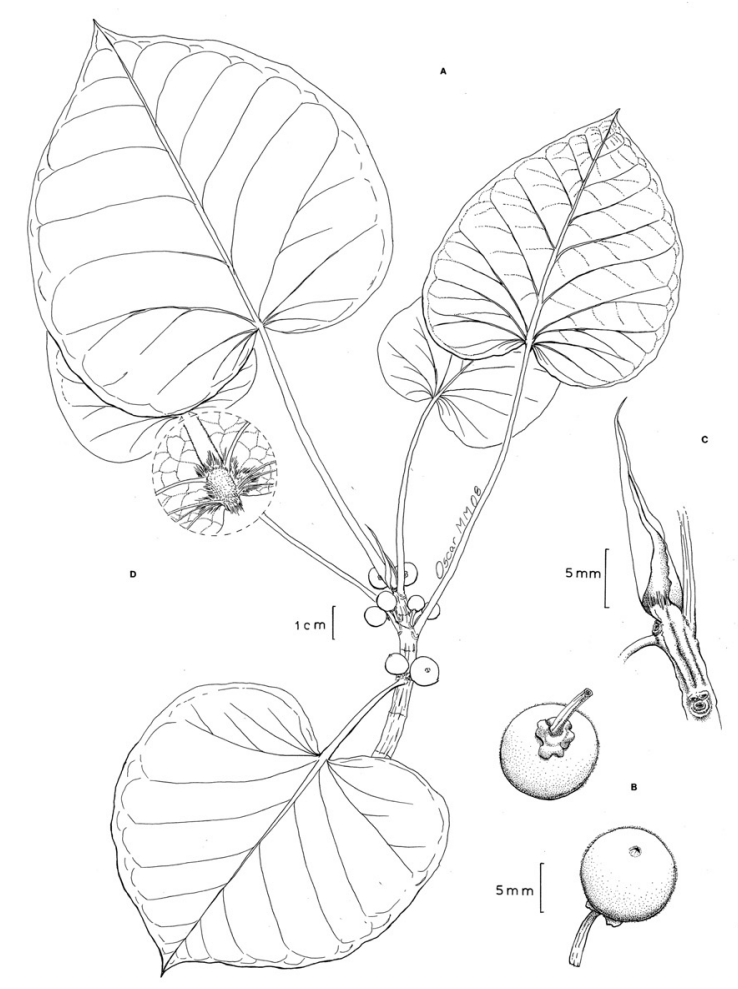

Figura 6. Ficus petiolaris (Durán 94). A, rama con hojas y siconos; B, yema foliar; C, brácteas basales y ostíolo de los siconos.

la vegetación de galería en el estado (8 especies) confirma lo descrito por Rzedowski (1978).

La distribución altitudinal del género en Guerrero, desde el nivel del mar hasta los $2100 \mathrm{~m} \mathrm{snm}$, coincide con los resultados de estudios previos efectuados en México (Ibarra-Manríquez y Wendt, 1992; Serrato et al., 2004; Piedra-Malagón et al., 2006; Carvajal, 2007). Se ha sugerido que en altitudes mayores la posibilidad de encontrar especies de Ficus decrece drásticamente, ya que el riesgo de que se presenten heladas se incrementa y esta clase de eventos acentúa la mortalidad de los polinizadores (Bronstein, 1989, Harrison, 2005).

De las especies endémicas de México presentes en Guerrero, F. petiolaris es la que tiene mayor distribución (13 municipios), lo que contrasta con $F$. lapathifolia, que hasta ahora únicamente se ha localizado en Atoyac de Álvarez. Entre las especies no endémicas, las más

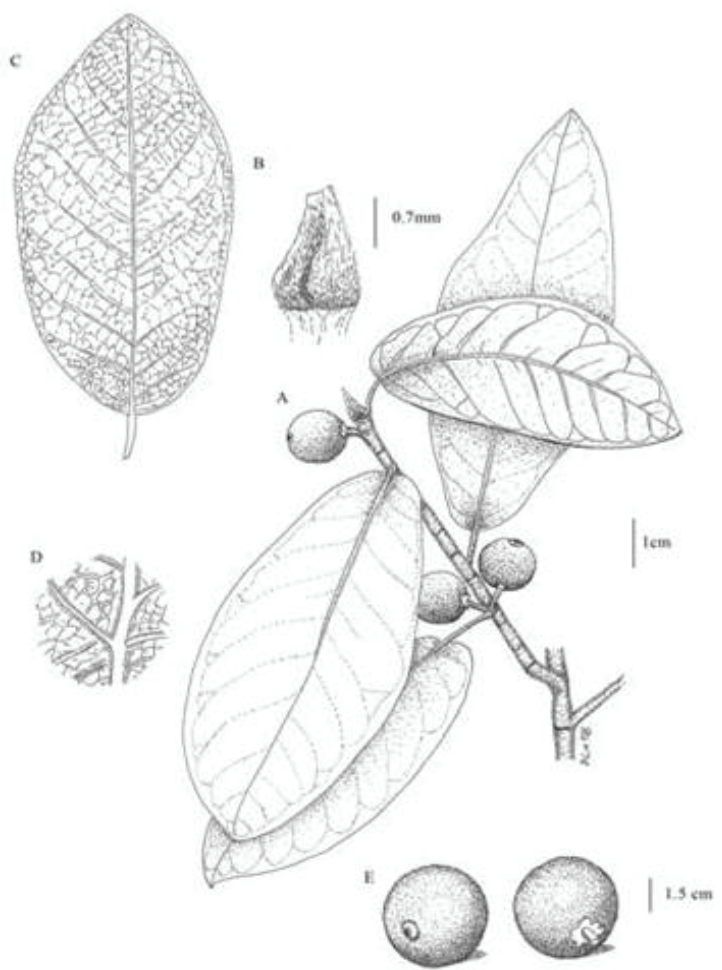

Figura 7. Ficus velutina (Durán et al. 125). A, rama con hojas y siconos; B, yema foliar; C, venación de la lámina foliar; D, detalle de la venación; E, brácteas basales y ostíolo de los siconos.

frecuentes en las entidades municipales fueron $F$. cotinifolia (36) y F. insipida (26). Estos taxones también fueron catalogados por Serrato et al. (2004) entre los de amplia distribución nacional. Ficus se ha recolectado en 50 de los 75 municipios de la entidad, lo que representa el $66.6 \%$ del total; entre los que destacan por su mayor cantidad de especies están Chilpancingo de los Bravo (11 especies), Atoyac de Álvarez (9), Acapulco de Juárez (8) y José Azueta (8). A pesar de que lo anterior apunta que la prospección florística para el género podría considerarse satisfactoria, se sugiere continuar con las expediciones botánicas en áreas poco exploradas, ya que es posible que el territorio guerrerense depare todavía la presencia de nuevos registros, como aconteció con $F$. yoponensis, colectada apenas en noviembre del 2008 o el caso ya explicado de $F$. aurea.

Es interesante que el número de especies en el 
municipio de Chilpancingo de los Bravo es el mismo que se contabilizó en la Estación de Biología Tropical Los Tuxtlas, Veracruz, que fue el área protegida con mayor cantidad de elementos del género en México (Serrato et al., 2004). Dada la carencia de reservas en Guerero, una estrategia inicial para seleccionar áreas de conservación podría tomar como punto de partida algunos de los resultados aquí presentados, por ejemplo, los municipios con mayor riqueza de especies o considerar las localidades de las especies endémicas o de las presentes en el bosque tropical caducifolio y en la vegetación de galería asociada a éste. Finalmente, la presente contribución se suma a evidencias previas que señalan el estado de Guerrero como uno de los territorios florísticamente más relevantes de México, que justifica plenamente incrementar esfuerzos que aseguren la conservación de sus tipos de vegetación, particularmente los bosques tropicales caducifolios y mesófilos de montaña.

\section{Agradecimientos}

A los curadores de los herbarios $\mathrm{CH}$, ENCB, F, FCME, HUAP, HUMO, IEB, INIF, MEXU, MO, UAMIZ y XAL, así como a la Dra. Nelly Diego, encargada del laboratorio de Plantas Vasculares, de la Facultad de Ciencias de la Universidad NacionalAutónoma de México, por su apoyo para la revisión de los ejemplares incluidos en el presente estudio. El primer autor agradece la beca de licenciatura con la que fue distinguido por el Programa de Apoyo a Proyecto de Investigación e Innovación Tecnológica (PAPIT, UNAM), dentro del proyecto "Diversidad y biogeografía del género Ficus (Moraceae) en México", clave IN229107-3; este proyecto también apoyó la consulta de los herbarios y el trabajo de campo. Las ilustraciones de las especies fueron amablemente realizadas por Ramiro Cruz Durán, Bibiana González y Óscar Montiel Morales. Un reconocimiento para José de Jesús Fuentes Junco y Nahú González Castañeda, por la elaboración de la figura 1. Nahú González y Ma. Guadalupe Cornejo Tenorio ayudaron en la captura de registros de la base de datos, la revisión de los herbarios y en el trabajo de campo. Por otro lado, Alberto Valencia García conformó la base de datos para facilitar la citación de los ejemplares consultados. Finalmente, las correciones y sugerencias de los árbitros anónimos ayudaron a mejorar el contenido del presente estudio.

\section{Literatura citada}

Berg, C. C. 1989. Classification and distribution of Ficus. Experientia 45:605-611.
Berg, C. C. 1990. Reproduction and evolution in Ficus (Moraceae): traits connected with the adequate rearing of pollinators. Memoirs of the New York Botanical Garden 55:169-185.

Berg, C. C. 2001. Moreae, Artocarpeae, and Dorstenia (Moraceae) with introductions to the family and Ficus and with additions and corrections to Flora Neotropica monograph 7. Flora Neotropica Monograph 83:1-346.

Berg, C. C. 2007. Proposals for treating four species complexes in Ficus subgenus Urostigma section Americanae (Moraceae). Blumea 52:295-312.

Berg, C. C. y J. F. Simomis. 1981. The Ficus flora of Venezuela: five species complexes discussed and two new species described. Ernstia 6:1-12.

Berg, C. C., M. Vázquez y F. Kooy. 1984. Ficus species of Brazilian Amazonia and the Guianas. Suplemento Acta Amazonica 14:159-194.

Berg, C. C. y X. Villavicencio. 2004. The species of Ficus in Bolivia. Ilicifolia 5:65-129.

Bronstein, J. L., 1989. A mutualism at the edge of its range. Experientia 45:622-637.

Burger, W. C. 1974. Ecological differentiation in some congeneric species of Costa Rica flowering plants. Annals of the Missouri Botanical Garden 61:297-306.

Burger, W. C. 1977. Moraceae. Fieldiana Botany 40:94-215.

Carauta, P. P. J. y B. E. Diaz. 2002. Figueiras no Brasil. Editora Universidade Federal do Rio de Janeiro. Rio de Janeiro. $211 \mathrm{p}$.

Carreto, B. y A. Almazán. 2005. Vegetación de la laguna de Tuxpan. Estudios florísticos en Guerrero 14. Prensas de Ciencias, Facultad de Ciencias, Universidad Nacional Autónoma de México. México, D. F. 32 p.

Carvajal, S. 1995. Nuevas combinaciones en especies del género Ficus L. (Moraceae subgénero Pharmacosycea) de México. Boletín del Instituto de Botánica de la Universidad de Guadalajara 1: 477-484.

Carvajal, S. 2007. Moraceae. Flora del Bajío y de regiones adyacentes 147:1-57.

Carvajal, S. y C. Peña-Pinela. 1997. Ficus jacquelineae (Moraceae, subgen. Urostigma) a new name for a Mexican fig. Boletín del Instituto de Botánica de la Universidad de Guadalajara 4: 57-59.

Carvajal, S., R. Rivera E. y H. Palacios J. 2001. Nuevas combinaciones en especies del género Ficus L. subgénero Urostigma (Moraceae) de México. Boletín del Instituto de Botánica de la Universidad de Guadalajara 8:127-136.

Ceballos, G. y A. García. 1995. Conserving Neotropical biodiversity: the role of dry forests in Western Mexico. Conservation Biology 9:1349-1356.

Cook, J. M. y J. Y. Rasplus, 2003. Mutualists with attitude: coevolving fig wasps and figs. Trends in Ecology and Evolution 18:241-248.

Corner, E. J. H. 1962. The classification of the Moraceae. Gardens Bulletin of Singapore 19:187-252.

Cué-Bär, E. M., J. L. Villaseñor, J. J. Morrone y G. IbarraManríquez. 2006. Identifying priority areas for conservation in Mexican tropical deciduous forest based on tree species. Interciencia 31:712-719. 
Diego-Pérez, N. 2000. lagunas Playa Blanca, El Potosí y Salinas del Cuajo y zonas circundantes. Estudios florísticos en Guerrero 10. Prensas de Ciencias, Facultad de Ciencias, Universidad Nacional Autónoma de México. México, D. F. $33 \mathrm{p}$.

Diego-Pérez, N. y L. Lozada-Pérez. 1994. Laguna de Tres Palos. Estudios florísticos en Guerrero 3. Prensas de Ciencias, Facultad de Ciencias, Universidad Nacional Autónoma de México. México, D. F. 29 p.

Felger, R. y C. Lowe. 1970. New combination for plant taxa in northwestern Mexico and southwestern of Unites States. Journal of the Arizona-Nevada Science 6:83.

Ferrusquía-Villafranca, I. 1998. Geología de México: una sinopsis. In Diversidad biológica de México: orígenes y distribución, T. P. Ramamoorthy, R. Bye, A. Lot y J. Fa (eds.). Instituto de Biología. Universidad Nacional Autónoma de México. México, D. F. p. 3-108.

Figueroa de Cotín, E. 1980. Atlas geográfico e histórico del estado de Guerrero. FONOPAS. Gobierno del estado de Guerrero. 171 p.

Fonseca, R. M. y L. Lozada P. 1993. Laguna de Coyuca. Estudios florísticos en Guerrero No. 1. Prensas de Ciencias, Facultad de Ciencias, Universidad Nacional Autónoma de México. México, D. F. 23 p.

Gallardo, C. 1996. Parque Ecológico La Vainilla, Zihuatanejo, Guerrero. Estudios florísticos en Guerrero 8. Prensas de Ciencias, Facultad de Ciencias, Universidad Nacional Autónoma de México. México, D. F. 61 p.

Gorelick, R. 2001. Did insect pollination cause increased seed plant diversity? Biological Journal of the Linnean Society 74:407-427.

Gual, D, M. 1995. Cañón del Zopilote (Área Venta Vieja). Estudios florísticos en Guerrero 6. Las Prensas de Ciencias, Facultad de Ciencias, Universidad Nacional Autónoma de México. México, D. F. 39 p.

Harrison, R. D. 2005. Figs and the diversity of tropical rainforests. BioScience 55:1053-1064.

Ibarra-Manríquez, G. 1991. Ficus (Moraceae): un género interesante para estudios en ecología y sistemática tropical. Ciencia 42:283-293.

Ibarra-Manríquez, G. y T. L. Wendt. 1992. El género Ficus, subgénero Pharamacosycea (Moraceae) en Veracruz, México. Boletín de la Sociedad Botánica de México 52:3-29.

Lozada, L. 1994. Laguna de Mitla. Estudios florísticos en Guerrero 2. Prensas de Ciencias, Facultad de Ciencias, Universidad Nacional Autónoma de México. México, D. F. 44 p.

Machado, C. A., N. Robbins, M. Thomas, P. Gilbert y E. A. Herre. 2005. Critical review of host specificity and its coevolutionary implications in the fig/fig wasp mutualism. Proceedings of the National Academy of Sciences 102:65586565.

Meza, L. y J. López G. 1997. Vegetación y mesoclima de Guerrero. Número especial 1. Prensas de Ciencias, Facultad de Ciencias, Universidad Nacional Autónoma de México. México, D. F. 53 p.

Olson, D.M. y E. Dinerstein. 2002. The Global 200: priority ecoregions for global conservation. Annals of the Missouri Botanical Garden 89:99-224.
Palacio-Prieto, J. L., G. Bocco, A. Velázquez, J. F. Mas, F. Takaki-Takaki, A. Victoria, L. Luna-González, G. GómezRodríguez, J. López-García, M. Palma, I. Trejo-Vázquez, A. Peralta, J. Prado-Molina, A. Rodríguez-Aguilar, R. MayorgaSaucedo y F. González-Medrano. 2000. La condición actual de los recursos forestales en México: resultados del Inventario Forestal Nacional 2000. Investigaciones Geográficas, Boletín Instituto de Geografía UNAM 43:83-203.

Pennington, T. D. y J. Sarukhán. 2005. Árboles tropicales de México. Manual para la identificación de las principales especies, tercera edición. Universidad Nacional Autónoma de México y Fondo de Cultura Económica, México, D. F. p. $142-145$.

Piedra-Malagón, E. M., Ramírez, R. y G. Ibarra-Manríquez. 2006. El género Ficus (Moraceae) en el estado de Morelos, México. Acta Botanica Mexicana 75:45-75.

Quintana, C. R. y S. Carvajal. 2001. Las especies jaliscienses del género Ficus L. (Moraceae). Boletín del Instituto de Botánica de la Universidad de Guadalajara 8:1-64.

Rzedowski, J. 1978. Vegetación de México. Limusa, México, D. F. 432 p.

Rzedowski, J. 1991. Diversidad y orígenes de la flora fanerogámica de México. Acta Botanica Mexicana 14:3-21.

Serrato, A., G. Ibarra-Manríquez y K. Oyama. 2004. Biogeography and conservation of the genus Ficus (Moraceae) in Mexico. Journal of Biogeography 31:475-485.

Shanahan, M., S. So, S. G. Compton y R. Corlett. 2001. Figeating by vertebrate frugivores: a global review. Biological Review 76:529-572.

Standley, P. C. 1917. The Mexican and Central American species of Ficus. Contributions from the United States National Herbarium 20:1-35.

Standley, P. C. 1922. Trees and shrubs of Mexico. Contribution of the United Sates National Herbarium 23:171-516.

Vargas, A. y A. Pérez. 1996. Cerro Chiletépetl y alrededores (cuenca del Balsas). Estudios florísticos en Guerrero 7. Prensas de Ciencias, Facultad de Ciencias, Universidad Nacional Autónoma de México. México, D. F. 49 p.

Velázquez, M. E., R. M. Fonseca y E. Domínguez. 2003. Bosque de Quercus en Tixtla de Guerrero. Estudios florísticos en Guerrero 16. Prensas de Ciencias, Facultad de Ciencias, Universidad Nacional Autónoma de México, México, D. F. $45 \mathrm{p}$.

Verduzco, C. y L. C. Rodríguez. 1995. El Rincón de la Vía. Estudios florísticos en Guerrero 4. Prensas de Ciencias, Facultad de Ciencias, Universidad Nacional Autónoma de México. México, D. F. 43 p.

Villaseñor, J. L. 2001. Catálogo de autores de plantas vasculares de México. Instituto de Biología, UNAM / Comisión Nacional para el Conocimientoy Uso de la Biodiversidad, México, D. F. 40 p.

Villaseñor, J. L. 2003. Diversidad y distribución de las Magnoliophyta de México. Interciencia 28:160-184.

Villaseñor, J. L. 2004. Los géneros de plantas vasculares de la flora de México. Boletín de la Sociedad Botánica de México 75:05-135.

Weiblen, G.D., 2002. How to be a fig wasp. Annual Review of Entomology 47:299-330. 